\title{
Giovanni Pontanos Poetik der admiratio
}

\subsection{Biographische Notizen}

Giovanni Pontano wurde 1426 in Cerreto bei Spoleto (Umbrien) geboren. Nachdem sein Vater, «Spross einer mächtigen Adelsfamilie»,1 ermordet worden war, begab er sich 1447 in den Dienst König Alfonsos von Aragonien. In Neapel arbeitete er in der « königlichen Kanzlei » und stieg Schritt für Schritt in immer höhere Funktionen auf. Im Laufe seiner politischen Karriere war er unter anderem Erzieher, Begleiter und Sekretär des Prinzen, Berater für strategische und militärische Fragen, Finanzminister und Kanzler. Nebenbei widmete er sich humanistischen Studien und erlernte die griechische Sprache. Unter Ferdinand I. von Aragonien hatte er in Perugia neben dem Kanzleramt auch den Lehrstuhl für Eloquenz inne. Das literarische Werk, dem er sich lange Jahre nur im Nebenamt widmete, rückte in seinen letzten Jahren ins Zentrum seiner Tätigkeiten.

Pontanos Schriften sind überaus vielseitig: Er hat eine Geschichte des Krieges zwischen König Ferdinand I. und Johann von Anjou (De bello Neapolitano) verfasst, grammatische, rhetorische, philosophische und philologische Abhandlungen geschrieben und auch naturwissenschaftliche Themen, vor allem der Astrologie und Astronomie, behandelt. Insbesondere ist er mit seinen ethischen Traktaten ${ }^{2}$ hervorgetreten. Nicht zuletzt aber zählen seine literarischen Werke zum «Erlesensten der neulateinischen humanistischen Dichtung ». ${ }^{3}$ Bis auf einige Trauergedichte (Nenia, 1498) erschien sein gesamtes poetisches Werk erst kurz vor seinem Tod oder posthum. Nur in wenigen Fällen lag eine autorisierte Drucklegung der Manuskripte vor. ${ }^{4}$

1 Alle Zitate in diesem Abschnitt entstammen der biographischen Einführung von HannaBarbara Gerl: Hanna-Barbara Gerl, Vita, in: Pontano, Dialoge, S. 29-30. Für biographische Angaben siehe ebenfalls Andrea Gustarelli, Introduzione, in: Giovanni Pontano, Dai „Carmina“. L'amore coniugale - I giambi - Le egloghe - La lira - Gli inni religiosi - Gli orti hesperidi, testo con traduzione a fronte e introduzione di Andrea Gustarelli, Milano 1934, S. 7-8.

2 De prudentia, De fortitudine, De liberalitate, De beneficentia, De magnificentia, De splendore, De conviventia, De obedientia, De immanitate, De fortuna, De principe.

3 Zu ihnen zählen insbesondere De amore coniugali, Eclogae, Versus iambici, Lyra, De laudibus divini, De hortis Hesperidum.

4 Siehe die Primärbibliographie in Pontano, Dialoge, S. 31-34. 
Nachhaltige Berühmtheit erlangte Pontano mit der Leitung der nach ihm benannten Accademia Pontaniana.

Sie [die Akademie] [...] bildete den Treffpunkt der gelehrten Welt von Neapel, die dort insbesondere philologische Dispute und philosophische und ethische Fragen behandelte. [...] Die Art der Gesprächsführung mit ihrer lockeren Themenverbindung und dem Kommen und Gehen der Teilnehmer sowie die komischen, ja satirischen Unterbrechungen und Einschübe geben vorzüglich den Rahmen der Akademie [...] wieder $^{5}$

Der poetologische Dialog Actius, der aufgrund seiner prominenten Behandlung der admiratio die zentrale Schrift dieses Kapitels sein wird, ist als Dialog der Akademie verfasst und weist die oben genannte «lockere Themenverbindung », das wechselnde Hervortreten einzelner Gesprächsteilnehmer zu bestimmten Themen sowie einen satirischen Auftakt auf.

Im Dialog werden Kriterien erläutert, die den poetischen Text eindeutig von anderen Textformen unterscheiden und das spezifisch Poetische definieren. Das Herzstück der poetologischen Überlegungen bildet die admiratio als Essenz der Dichtung. ${ }^{6}$ Vor dem theoretischen Hintergrund des Actius werde ich literarische Beispiele aus den Eclogae und De hortis Hesperidum in meine Analyse einbeziehen. Alle untersuchten Texte sind zur gleichen Zeit oder nach der Niederschrift des Actius verfasst worden. Die Frage, ob Pontanos Poetik der admiratio sich darin niederschlägt, scheint mir deshalb von besonderem Interesse zu sein. ${ }^{7}$

5 Gerl, Vita, S. 30. Pontano war ab 1471 Präsident der Akademie. Vgl. ebenso Hélène Casanova-Robin, Metamorphosen und intime Fabel. Pontanos Ovidrezeption in den Eclogen, den Tumuli und in De hortis Hesperidum, in: Henriette Harich-Schwarzbauer und Alexander Honold (Hgg.), Carmen perpetuum. Ovids Metamorphosen in der Weltliteratur, Basel 2013, S. 65 .

6 Véronique Denizot, „Comme un souci aux rayons du soleil". Ronsard et l'invetion d'une poétique de la merveille (1550-1556), Genève 2003, S. 77 : « Avec l'Actius de Giovanni Pontano, l'admiration devient le pivot autour duquel se dessine la spécificité de la poésie [...]» // Casanova-Robin, Étude introductive, S. XXIII: «L'Actius présente une définition de l'essence même de la poésie [...]: la poésie doit frapper les ésprits, faire naître l'admiratio et pour cela tendre vers le sublime, grâce à l'excellentia de sa facture. »

7 Francesco Arnaldi, Nota introduttiva, in: Giovanni Gioviano Pontano, Poesie latine. Scelta, a cura di Liliana Monti Sabia, Torino 1977, S. XV. 


\subsubsection{Ein prophetischer Traum}

Giovanni Pontano bemängelt die formale Stilkritik, ${ }^{8}$ wie er sie bei einigen Zeitgenossen, unter anderem bei Lorenzo Valla, ${ }^{9}$ am Werk sieht. Perrine Galand stellt dies folgendermassen dar:

Pontano reproche à la critique grammaticale d'oublier, dans son obsession du détail érudit, la recherche et l'évaluation de la signification profonde de la poésie perceptible à travers sa forme..$^{10}$

Er versucht deshalb, nicht auf einer stilistischen Ebene stehen zu bleiben, sondern erweitert und verbindet seine Analysen im Hinblick auf die Ergründung einer tieferen Bedeutungsebene, die auf dem Zusammenspiel aller sprachlicher und inhaltlicher Elemente basiert. ${ }^{11}$

Pietro Summonte, der Herausgeber von Pontanos Werken, weist in seinem Brief an Francisco Puderico, der als Vorrede der ersten Ausgabe des Actius von 1507 beigelegt ist, auf die neue und bewundernswerte («admiranda ») Vorgehensweise Pontanos hin. Diese unterscheidet sich von den Grammatikern durch ihren performativen Charakter.

Non enim ab aliquo fortasse grammatico de re poetica deque historica disputatur, sed ab illo praecipitur Ioviano Pontano, cuius quidem in utroque genere post tot annorum depravationem nova quaedam admirandaque apparet felicitas, ut

8 Giacomo Ferraù, Pontano critico, Messina 1983, S. 13.

$9 \quad$ Lorenzo Valla hat philosophische Probleme als linguistische konzipiert. So hat er unter anderem Aristoteles' neun Kategorien auf drei Kategorien reduziert (substantia, qualitas, actio), die sprachlich dem Nomen, dem Adjektiv und dem Verb entsprechen. Ebenfalls hat er klassische Autoren wie zum Beispiel Cicero und Titus Livius, zwei von Pontanos verehrten Autoren, nur auf stilistischer Ebene rezipiert, ohne - so Pontano - auf deren literarische Einheit einzugehen, die für das Gesamtwerk und dessen Aussagegehalt entscheidend ist. Für Pontano ist Kritik essenziell, aber sie darf nicht nur auf formaler Ebene stattfinden. Gestört hat Pontano auch Vallas Haltung, sich als alleinigen „Hüter“ der lateinischen Sprache zu inszenieren, so in den Elegantiae linguae Latinae - der ersten lateinischen Grammatik seit der Spätantike. Konsultiere zu Valla https://www.britannica. com/biography/Lorenzo-Valla (Stand Arpil 2021).

10 Galand-Hallyn, Maître et victime, S. 107.

11 Jorge Ledo sieht bei Pontano das Prinizip «form over content» am Werk. Pontano aber betont, dass es ihm um die passende Form für einen bestimmten Inhalt gehe, dass Inhalt und Form nur zusammen betrachtet werden könnten. Vgl. LEDo, Some remarks, S. 178. 
non iniuria saepa a te illud usurpatum sit, coepisse eum [...] et facere pariter et docere. ${ }^{12}(288)$

Er hebt hervor, dass Pontano begonnen habe, « in gleichem Maße zu handeln und zu lehren», das heisst seine Prinzipien in seinen Lehren sogleich zur Anwendung kommen zu lassen.

Die Vermittlung der admiratio gelingt besonders, wenn sie in den Lesern oder Zuhörern unmittelbar hervorgerufen wird: Einer der Gesprächsteilnehmer ruft dazu auf, das über die Dichtung Gesagte nicht nur anzuerkennen und zu loben, sondern darüber zu staunen («admirari »), wie Actius den Weg «zur Erweckung der Bewunderung in der Dichtung» aufgezeigt habe. Laut Pontano kann der Dichter am besten und «mit Würde über die dichterischen Tugenden sprechen », weil er die Tugenden - insbesondere die admiratio als höchste aller Dichtertugenden - als poetische Verfahren einbeziehe und vorführe (414-415).

Der Dialog beginnt als Literaturkritik. Die Gesprächsteilnehmer ${ }^{13}$ analysieren Verse Vergils und Livius'14 und leiten daraus die spezifischen Eigenheiten poetischer Texte im Vergleich zu historiographischen oder rhetorischen Redeformen ab. Die Analysen dienen dazu, Vergil vom kleinsten Element an als höchsten aller Dichter zu feiern ${ }^{15}$ und Titus Livius den Vorrang unter den

12 Alle Zitate und Übersetzungen aus dem Actius stammen aus folgender, bereits genannter Ausgabe: Giovanni Pontano, Dialoge, Lateinisch / Deutsch, übersetzt und herausgegeben von Hermann Kiefer, München 1984: «Denn hier spricht nicht irgendein Grammatiker über Dichtkunst und Geschichtsschreibung, sondern es lehrt sie Iovianus Pontanus, dessen glückliche Natur in beiden Gattungen nach so vielen Jahren des Niedergangs als neuartig und bewunderungswürdig erscheint, sodass Du nicht zu Unrecht oft behauptest, jener habe [...] angefangen, in gleichem Maße zu handeln und zu lehren. » // Während Perrine Galand-Hallyn und Vittorio Rossi (Il Quattrocento, Milano 1938, S. 489) Pontano in der Tradition von Georgios Trapezuntius - der als Erster die lateinischen Traktate von Cicero und Quintilian an jene der Griechen Dionysios von Halikarnassos und Hermogenes annäherte - verorten, verbindet Concetta Carestia Greenfield das Vorgehen Pontanos mit jenem von Polizianos Miscellanea. Trapezuntius folgt strengen Normen, während Poliziano - und auch Pontano - Raum für eine poetische Literaturkritik schaffen, die selbst poetische Verfahren anwendet und sich in einer relativ freien Form präsentiert. Siehe Gre en fie LD, Humanist and Scholastic Poetics, S. 278.

13 Zu den Rednern gehören der Senex (Poetik), Actius Syncerus (Poetik), Paulus Prassicius (Rhetorik), Gabriel Altilius (Historiographie), Ioannes Pardus (Traumlehre, Aristoteliker), Franciscus Podericus (Moderator).

14 Galand-Hallyn, Maître et victime, S. 107.

15 Gernot Michael MüLler, VielfaltundEinheit.DieDichtungslehre in GiovanniPontanos Actius im Horizont einer Dialogpoetik der varietas, in: MARC FöCKING und BERNHARD Huss (Hgg.): Varietas und Ordo: zur Dialektik von Vielfalt und Einheit in Renaissance und Barock, Stuttgart 2003, S. 40: «Ziel ist es, eine für die [...] besprochene Textsorte jeweils 
Geschichtsschreibern zu sichern. Dabei soll gezeigt werden, dass deren Texte aus staunenswerten Elementen bestehen und ihre bleibende Wirkung daher rührt, dass ihr Schaffen ganz im Zeichen der admiratio steht.

Actius Syncerus - nach dem der Dialog benannt ist - ist der akademische Name Jacopo Sannazaros (1458-1530), ${ }^{16}$ der dem neapolitanischen Dichter 1478 beim Eintritt in die Accademia Pontaniana verliehen wurde. Actius tritt als akkurater Kenner Vergils und als Nachfolger und Bewunderer seines Lehrers, des Senex - Pontanos Name in der Akademie -, hervor. Der Senex und Actius verkörpern das perfekte Schüler-Lehrer-Paar: Beide sind Gelehrte und Dichter, beide vertreten die Ansicht, dass die grossen Dichter minutiös studiert wie auch bewundert und verehrt werden müssen, um eine tiefgreifende Kenntnis ihrer Texte zu erlangen. Summonte feiert Actius in der Vorrede als neuen «Pontano» (292). In der Vorrede (293) wie auch im Dialog legen sich die Figuren teilweise übereinander, sodass nicht mehr unterschieden werden kann, ob vom alten (Pontano) oder vom neuen Pontanus (Sannazaro) die Rede ist.

Der Dialog setzt nach einer «komödienhafte[n] Einführung» über den Verkauf eines Häuschens an einen naiven Schweinehirten und Actius' « ironische[r] Stellungnahme [...] zur Dummheit und Pseudoreligiosität der handelnden Personen » (281) mit einer Klage über die lasterhafte Gegenwart ein. Als Gegenpol erinnert sich Actius an seinen verstorbenen Freund Ferrandus Januarius, der als Abt in Neapel wirkte und eindrucksvolle Reden über die Kirchenväter, über Franziskus und Dominikus und deren Prinzipien der Einfachheit und Bescheidenheit hielt (303). Seine Redeweise löste in höchstem Masse Staunen und Bewunderung bei seinen Zuhörern aus («summa etiam cum admiratione», 302), da er eine ungewöhnlich kraftvolle Eloquenz mit Entrüstung verband. Dadurch gelang es ihm, seine Erregtheit auf die Zuhörer zu übertragen (302).

Actius berichtet seinen Gesprächspartnern von einem sonderbaren Traum, in dem ihm der verstorbene Freund erschien.

Es erscheint ihm [Sannazaro] ein verstorbener Freund, Ferrandus Januarius, mit dem er sich einst oft über die Unsterblichkeit der Seele unterhalten hatte; jetzt fragt er ihn, ob die Ewigkeit und Schrecklichkeit der Höllenstrafen Wahrheit

angemessene Poetik aus der Analyse der als unübertreffbar erkannten Autoren heraus zu entwickeln.»

16 Jacopo Sannazaro war ein neapolitanischer Dichter, der sowohl italienische als auch lateinische Werke verfasste. Insbesondere mit seiner bukolischen Romanze Arcadia, die eine Vielzahl europäischer Dichter beeinflusste, sowie mit seinem Bibelepos De partu virginis hat er Berühmtheit erlangt. 
sei? Der Schatten antwortet nach einigem Schweigen ganz im Sinne des Achill, als ihn Odysseus befragte: « So viel sage und beteure ich dir, dass wir vom leiblichen Leben Abgeschiedenen das stärkste Verlangen tragen, wieder in dasselbe zurückzukehren. » Dann grüßt und verschwindet er. ${ }^{17}$

Paulus, einer der Gesprächsteilnehmer, ist von der Erzählung bestärkt und von Staunen erfüllt. Er fordert Actius auf, mehr über die wunderliche («mirifice») Begebenheit zu erzählen (305).

Actius selbst ist doppelt affiziert vom Staunen: von wunderbarer Freude («mira voluptas ») über das Erscheinen des Freundes und von Verwunderung («admiratio »), als ihm bewusst wird, dass der Freund eigentlich schon lange tot ist. Dieser mehrschichtige Zustand aus Staunen und Verwunderung lässt ihn zweifeln über die Unterscheidung von Traum und Realität: Ist der Freund tatsächlich tot oder träumt er das nur? Ist die lebendige Erscheinung des Freundes echt oder nur geträumt?

Cepit eodem me puncto temporis mira voluptas amici iam reducis, cepit admiratio, quod mortuum iam dudum illum esse subiit recordatio; cepit rursum dubitatio, quia vivum illum cernebam et loquentem quidem et vivi hominis munus sermone, vultu affectibusque implentem: num mortuum arbitrarer, an potius illius mihi obitus somnianti esset visus qui re ipsa iam viveret? ${ }^{18}$ (306)

Im Traum erzählt der Freund, das grösste Verlangen der Seelen im Jenseits sei die Rückkehr ins Diesseits und die Wiedervereinigung mit dem Körper. Die Nachricht aus dem Jenseits erzeugt Staunen und steigert die Aufmerksamkeit der Gesprächsteilnehmer (diegetisch) und Leser (extradiegetisch).

Im Laufe des Textes wird sich der wunderbare Inhalt einer Aussage oder eines Textes, insbesondere auch dessen fiktionaler Gehalt, immer wieder als interdependent zum Staunen erweisen. Grassi formuliert diese Abhängigkeit als elementares Prinzip der Poetik Pontanos:

Pontano's thesis is that poetry is rooted in the miraculous (mirabile) and that poetry must express the mirabile in a way that awakens admiration (admiratio) in the listener or reader. [...]

17 Jacoв Burckhardt, Die Kultur der Renaissance in Italien. Ein Versuch, Stuttgart 2009 [186o], S. 449 .

18 Eben zu diesem Zeitpunkt hat mich das wunderbare Entzücken über den zurückgekehrten Freund ergriffen, die Verwunderung hat mich ergriffen, weil die Erinnerung aufstieg, dass er schon lange tot war; wieder hat mich der Zweifel ergriffen, weil ich ihn leben und sprechen sah und wie er die Rolle eines lebenden Menschen im Sprechen, in der Miene und in den Empfindungen ausfüllte: sollte ich ihn für tot halten oder erschien mir eher im Traum der Tod, während er tatsächlich noch lebte? 
The internal relationship between the mirabile, „wonderful“ object of poetry and language that inspires admiration forms the deep structure of poetic expressions and determines its original and revelatory character. ${ }^{19}$

Nach einem kurzen Exkurs über die Natur des Traums sowie einigen leichteren grammatikalischen Fragen kehrt der Gesprächskreis zum Traum zurück, um näher auf die Traumbilder einzugehen. Alle Menschen träumen, aber nur den vates zeigen sich prophetische Traumbilder. Die Dichter sind den Weissagenden ähnlich, weshalb für beide die Bezeichnung vates verwendet wird:

Quodque poetica vis vaticinantium habetur persimilis, unde poetae et ipsi vates dicuntur, Synceri ipsius, poeticae quam studiosissimi vel poetae potius et quidem elegantissimi, officium neque indignum fuerit neque ingratum, si et ipse consessu in hoc de poetis afferet in medium aliquid $[\ldots]^{20}\left(33^{2}\right)$

Mit dem Vergleich von Dichtung und Weissagung wird der Dialog auf das eigentliche Diskussionsthema - «über das Vortreffliche der Dichtung zu handeln » (333) - übergeleitet.

Gleich zu Beginn schickt Actius voraus, dass eine Rede über die excellentia der Dichtung «grössere Muße und wachsamere Sorgfalt » erfordere als die vorangehenden Themen, denn «die Aufgabe oder das Ziel eines Dichters [sei es], angemessen zur Bewunderung [ad admirationem] zu sprechen; aber nichts außer dem ganz Vortrefflichen bring[e] Bewunderung hervor » (333).

Ganz kurz und quasi nebenbei wird auf die «Majestät» des Aristoteles verwiesen, der als Philosoph anerkannt wird, dessen Prinzip der mesotes jedoch unvereinbar mit dem Prinzip der excellentia, wie es im Dialog entwickelt wird, zu sein scheint. Der Dialog verweist darauf, dass die aristotelische

19 Ernesto Grassi, Humanistic Rhetorical Philosophizing: Giovanni Pontano's Theory of the Unity of Poetry, Rhetoric, and History, in: Philosophy \& Rhetoric 17 (1984), S. 142, 144.

20 Und weil die Dichtung der Kraft der Weissagenden für ganz ähnlich angesehen wird, weshalb die Dichter auch Seher genannt werden, wäre es die Aufgabe von Syncerus der der Poesie oder besser einem Dichter, und zwar dem elegantesten, außerordentlich zugetan ist -, es wäre also seine weder unwürdige noch undankbare Aufgabe, wenn er in dieser Versammlung etwas über die Dichter vorbrächte [...] // Genauso wie die Kraft der Weissagung nur wenigen beschieden ist, gibt es nur « wenige oder vielmehr seltene Dichter, bei denen man auch glaubte, die Kraft ihres Ingeniums ströme vom Himmel » (331). Diese Auserwählten besitzen eine Vertrautheit mit den göttlichen Visionen, weil sie vom Himmel « jene Geformtheit [erhalten haben], die zur Aufnahme der geschauten Dinge befähigt ist, welche vom Himmel durch Schwingungen herabgleiten » (331). Vgl. dazu auch Inst. Orat., VI, 3o. Pontano versteht das Wort der Dichtung als „weisendes“ (« indicative»), nicht - wie beispielsweise Valla - als „be-weisendes“ («discoursive»). Siehe Grassi, Humanistic Rhetorical Philosophizing, S. 147. 
Ausgewogenheit nicht mit der excellentia verglichen werden kann. Mesotes ist aus ethischer Sicht zentral, Tugenden entstehen aus einer ausgewogenen Mitte heraus, sie sind weder über- noch untertrieben. Tugendhaftigkeit ist nicht nur die Basis jeder Dichtung, sondern auch der admiratio, somit ist die ethische Ausgewogenheit als vorgelagertes Prinzip bereits gegeben (333). Anders verhält es sich mit der Stilhöhe der poetischen Sprache: Hier gilt nicht das Prinzip der Mitte, sondern der Vortrefflichkeit (excellentia). Die Sprache der Dichtung hat sich stets auf der höchsten aller Ebenen anzusiedeln und soll sich, ganz im Sinne von Aristoteles' Rhetorik, von der unauffälligen Alltagssprache differenzieren. ${ }^{21}$

\subsubsection{Kunstfertigkeit und sinnliches Erstauntsein}

La perception du mirabile est subordonnée à la qualité de la voix poétique, dont la musicalité doit être à la mesure du merveilleux représenté. Pontano se montre surtout exigeant pour la prosodie, le rythme et les sons, ainsi que pur la compositio verborum, tous points qui concourent à l'expressivité du poème. ${ }^{22}$

Für Pontano beginnt das Vortreffliche der Dichtung auf der sprachlichstilistischen Ebene, das heisst mit den kleinsten Einheiten des dichterischen Textes, weshalb er mit einer Analyse der Versmasse in seine Ausführungen einsteigt.

Numerus autem ipse cum primis et movet et delectat et admirationem gignit. Eius autem prima illa laus est quod varietatem parit $[. . .]^{23}\left(33^{2-}-334\right)$

Mirum est etiam quantum tum litterae tum syllabae aut adiungant numerositati aut demant ab ea, cum vocalium aliae sint plenae ac sonorae, aliae eiles, clarae aliae aut contra subobscurae, omnes denique pro natura coniunctarum consonantium aliam atque aliam qualitatem suscipiant, proque loco collocationis, ubi primae ultimaeve aut mediae fuerint in costituendis dictionibus. ${ }^{24}(398)$

21 Rhet., 1404b.

22 Casanova-Robin, Étude introductive, S. CCXLVIII.

23 Das Versmaß aber bewegt zuallererst und erfreut und erzeugt Bewunderung. Sein erstes Lob ist, dass es die Verschiedenheit hervorbringt [...]

24 Wunderbar ist auch, wieviel die Buchstaben und sogar die Silben zur Rhythmik beitragen oder sich von ihr entfernen, da einige Vokale voll und klingend, andere kraftlos, andere hell oder umgekehrt ein wenig dunkel sind, und schließlich alle je nach der Natur der verbundenen Konsonanten bald diese, bald jene Eigenschaft annehmen, ebenso je nach Ort der Zusammenstellung, wo die ersten oder die letzten oder die mittleren Buchstaben bei der Zusammensetzung der Wörter waren. 
Durch Verzögerung und Beschleunigung, durch die vielfältige Abfolge - das Zusammenstossen oder Ineinanderübergehen - der Vokale wird «bald eine Ernsthaftigkeit im Sprechen, bald eine Würde [...] erreicht», die zur admiratio führt («admirationis [...] duces», 334). ${ }^{25}$ Neben varietas ${ }^{26}$ und «bewunderungswürdige [r] Zusammenstellung» - die zwar höchst kunstvoll gestaltet sein, dennoch aber natürlich "fliessen“ soll (373) - sind Erhabenheit und Würde die zentralen Kriterien zur Erreichung des wirkungsästhetischen Ziels der admiratio (vgl. dazu insbesondere 410-411). Diese « bewundernswerte Kunstfertigkeit» («mirabili artificio», 376) wurde von Vergil perfektioniert: Er gilt als vielfältigster aller Dichter - sowohl auf stilistischer wie auch auf thematischer Ebene - und hat wie kein anderer mit seinen Versen admiratio erzielt. Pontano streicht die Präzision und das Feingefühl Vergils heraus, wenn er davon berichtet, wie erstaunlich es sei («mirum est», 334), dass sich der Vers vollkommen verändere, er an Würde, Erhabenheit und Grossartigkeit verliere, wenn auch nur eine Kleinigkeit geändert oder umgestellt werde.

Die Rhythmen der Poesie schmeicheln den Ohren und je unerwarteter, vielfältiger oder ausgefallener sie sind, desto erfreuter ist das Gehör. Damit sind sie nicht nur wichtige Elemente, um admiratio hervorzurufen, sondern auch, um die Aufmerksamkeit der Hörer zu erlangen und sie vor Langeweile zu bewahren. Freude und Vergnügen gehen bei Pontano mit dem Staunen einher, was sich an oft benutzten Formulierungen wie « erfreut in wunderbarer Weise » (« delectat mirifice », 398-399) zeigt. $^{27}$

Dem Gehör kommt eine besonders wichtige Rolle zu, da es als erste Instanz über einen poetischen Text verwundert oder erstaunt ist. ${ }^{28}$ Das sinnliche

25 Die Qualitäten der Ernsthaftigkeit und der Würde werden als Bedingungen der admiratio bezeichnet. Für weitere Passagen siehe die Seiten 335, 343, 345, 411-412.

26 Varietas ist wie für Poliziano auch für Pontano eines der zentralsten Mittel, um admiratio zu erzeugen, vgl. z. B. S. 463 .

27 Vgl. ebenso S. 354: «Affert autem raritas haec hiandi cum insequenti versu non sine aurium voluptate etiam dignitatem; nam et novitas delectat ipsa per se [...] (Die folgende Hiatbildung mit dem nächsten Vers bewirkt nicht ohne Vergnügen für das Ohr auch Würde; denn etwas Neues erfreut schon an sich [...]) » Eine analoge Stelle findet sich auf Seite 360 .

28 Es könnte scheinen, als handle Pontanos Dialog nur von vorgetragenen Texten. Pontano verweist aber abwechselnd sowohl auf Leser wie auch auf Zuhörer. Wichtig als erste Reaktion ist das Sinnliche - sei es das effektiv Sinnliche oder aber das imaginäre, innerlich wahrgenommene Sinnliche. Zum Vorrang des Auditiven vgl. auch Inst. Orat., IX, $4,116$. 
Erstauntsein ist die notwendige Bedingung dafür, um überhaupt einen Zugang zum Gedicht zu erhalten (412). ${ }^{29}$

An die Auswahl des Versmasses schliesst sich die kluge und sorgfältige Kombination von Silben, Wörtern und Sätzen an (411). Nicht zuletzt sollen Klang- und Wortwahl der Verse ihrem Inhalt angepasst sein, sich scheinbar natürlich aus den Gegenständen, Topoi und Figuren ergeben. Wird von einem Kampf berichtet, soll die kämpferische Stimmung in Rhythmus, Klang, Wortwahl widergespiegelt werden und in den Zuhörern die entsprechende Reaktion - in diesem Fall den Schrecken des Kampfes - auslösen. Admiratio stellt sich gleichwohl ein, und zwar übergeordnet als Staunen darüber, dass mittels Dichtung eine solche Wirkung erzielt werden kann.

\subsubsection{Dichtung und Geschichte: Ausdruck der Fantasie}

Altilius führt die Argumentation fort, indem er die Dichtung mit der Geschichtsschreibung vergleicht und das Prinzip der admiratio auf stofflicher Ebene illustriert.

Vieles haben Dichtung und Geschichtsschreibung gemeinsam: Beide Textformen zielen darauf, etwas an die Nachkommen weiterzugeben, «die Erinnerung an sich möglichst dauerhaft zu machen» (421). Sie kommen " wunderbarerweise überein, dass es beider Thema ist zu erleuchten [...] und das Erzählte - soweit sie können - zu verewigen » (423). Von Cicero wurde die Geschichte als «Dichtung in Prosa » bezeichnet, was Altilius als noch immer geltende Regel zu erweisen sucht. Sowohl Dichtung wie auch Geschichte sind der horazischen Trias von docere, movere et delectare verpflichtet, sie wollen nützlich sein, das Gesagte vor Augen führen, das Gute hochhalten, das Schlechte herabsetzen (421).

[...] pleraque enim habent inter se communia: ut rerum vetustarum ac remotarum repetitiones, ut locorum, populorum, nationum, gentium descritpiones, quin etiam illorum situs, mores, leges, consuetudines, ut vitiorum insectationes, virtutum ac benefactorum laudes; utraque enim demonstrativo versatur in genere, nec minus etiam in deliberativo [...] utraque etiam gaudet

29 An diese Voraussetzung erinnert Emil Staigers Kunst der Interpretation (1955). Der musikalische Gehalt wird nur in Bezug zur Sprache erläutert. Metaphysische Hinweise auf himmlische Schwingungen, wie wir sie bei Platon und in der Folge auch bei Poliziano finden, klingen bei Pontano nur schwach an (vgl. S. 331). Zum Verhältnis von Klang und admiratio siehe Francesco Tateo, La poetica di Giovanni Pontano, in: Filologia Romanza 6 (1959), S. 299. 
amplificationibus, digressionibus item ac varietate, studetque movendis affectibus sequiturque decorum quaque in re ac materia suum. ${ }^{30}(420)$

Auch in der Auswahl von «Sachen und Worten» unterscheiden sich Geschichtsschreibung und Dichtung nur insofern, als die Geschichte keuscher («castior», «castigatior») ist, während die Dichtung freimütiger und ausschweifender («lascivior», «liberalior», «affectatior») sein darf. ${ }^{31}$ Das historische Vokabular ist gemässigter, orientiert am Bestehenden und Bekannten. Pontano vergleicht die Geschichte mit einer « gewöhnlichen », die Dichtung hingegen mit einer « edlen [...] Frau » (423).32 Dichtung übertreibt, sie zieht fremde oder antike Vokabeln bei oder schafft gar neue Wörter und Wortkombinationen - sie kreiert eine poetische Welt jenseits des Alltäglichen.

Der entscheidende Unterschied zwischen Dichtung und Geschichtsschreibung liegt in ihrem Zweck begründet. Zielt die Geschichte darauf, die Wahrheit darzustellen, ${ }^{33}$ geht es der Dichtung einzig darum, wunderbar und bewundernswert zu sein. Dazu kann sie das Terrain der Wahrheit verlassen, Wahrscheinliches oder Erfundenes hinzufügen - wenn es zur admiratio beiträgt (423). Der Dichter kann sein Figurenarsenal frei erweitern, «Götter, Nymphen und andere Gottheiten, Seher und Rasende » in die Erzählung einflechten (423). Die Fiktion steht im Dienst der Dichtung und ist eines der wirksamsten Mittel, um admiratio zu erzeugen.

$30 \quad[. .$.$] denn sie [Dichtung in Versen und Dichtung in Prosa, d. h. Geschichte] haben das$ meiste miteinander gemeinsam, z. B. die Wiederholungen altehrwürdiger und entfernter Dinge, die Beschreibungen von Orten, Völkern, Nationen und Stämmen, ja sogar deren Lage, Sitten, Gesetze, Gewohnheiten und die Verfolgungen von Lastern und das Lob der Tugenden und Wohltaten; denn beide gehören zur demonstrativen und ebenso zur deliberativen Gattung [...] auch freuen sich beide über Erweiterungen, ebenso über Ausschweifungen und die Mannigfaltigkeit; beide suchen die Leidenschaften zu bewegen und folgen in jeder Sache und jedem Stoff dem sie Zierenden.

31 Das Überschwängliche der Dichtung wird auch im früheren Dialog Antonius am Beispiel Vergils betont. Giovanni Pontano, Antonius, in: Ders., Dialoge, S. 182-185: « At Virgilius et aures et oculos et animum admiratione implet [...] Sed haec exuperantia poetarum est propria et haud scio an alibi magis quam hic deceat. (Jedoch erfüllt Vergil Ohren, Augen und das Herz mit Bewunderung [...] Aber dieser Überschwang ist den Dichtern eigentümlich, ich weiss nicht, ob er sich anderswo mehr schickt als hier.) 》 Vgl. dazu ebenfalls Ferraù, Pontano critico, S. 23.

32 Ein weiterer Vergleich ist jener der «Hausfrau» (Historiographie) mit der Frau, die auf der «Schaubühne » zu Hause ist (Dichtung; 423).

$33[\ldots]$ cum altera veritati tantum explicandae [...] (423). // Vgl. ebenso Marcus Tullius Cicero, De oratore, Lateinisch / Deutsch, übersetzt, kommentiert und mit einer Einleitung herausgegeben von Harald Merklin, Stuttgart 1981, 2, 62; ebenso Pontano, Dialoge, S. 451. 
quod vocem quoque dat et orationem rebus mutis, divinitatem tribuit insomniis, Deos etiam ipsos mortalibus instruit affectionibus. ${ }^{34}(422)$

Oportet enim perhuberem esse eam perque affluentem, cum necesse sit, multa, diversa, varia hinc atque illinc apportata et disquisita colligat collectaque quasi pleno e sinu effundat, ut quae mirabiliter quoque inventa videantur; [...] $]^{35}$ (464)

Quo enim maiora atque admirabiliora quae ab ipsis dicuntur appareant, humana ad deos transferunt, fingunt monstra, mittunt insomnia, deos denique in homines vertunt. ${ }^{36}(5 \mathrm{O} 4)$

utque implere generosos illos spiritus quacunque ratione poetae valeant, coelestes etiam res mortalium rebus inseruisse eos refersisseque carmen suum commentis atque fabulis, quibus ipsa sullimitas ad summum usque, hoc est ad admirationem incresceret; $[\ldots]^{37}(506)$

Dennoch verfügt auch die Historiographie über einen kleinen Fiktionsspiel-
raum, da sie die Ursachen und Vorüberlegungen, die den Ereignissen voraus-
gehen, darzulegen sucht. ${ }^{38}$ Die Fiktion steht dann jedoch nicht im Dienst

34 Auch den stummen Dingen gibt sie Stimme und Rede, sie teilt den Träumen göttliche Bedeutung zu und stattet sogar die Götter mit menschlichen Gemütsbewegungen aus.

35 Denn sie [die mirum celeritas des Textes] muss überreich und überfließend sein, da es notwendig ist, dass sie Vieles, Verschiedenes und Mannigfaches, hie und da Zusammengetragenes und Untersuchtes sammelt und das Gesammelte gleichsam aus vollem Busen ausschüttet, sodass es auch wunderbar erfunden zu sein scheint. // Zur celeritas vgl. insbesondere die Ausführungen zu Sallust, Seite $453 \mathrm{ff}$., mit einer Klimax auf Seite 467. Hier wird die Raschheit als Bild für die discordia concors verwendet, als fliessenden Strom, in den alles Unterschiedliche sich einfügt, aber alles an seinen richtigen Ort fliesst und keine Verwirrung entsteht - «wie ein fischreicher Fluss von vielen und klaren Gewässern » (465).

36 Damit ihre Worte nämlich umso größer und bewundernswerter erscheinen, übertragen sie Menschliches auf die Götter, erdichten sie Ungeheuer, schicken sie Träume und verwandeln sie schließlich die Götter in Menschen.

37 Und damit die Dichter jene edlen Geister auf jede beliebige Art zu erfüllen vermöchten, hatten sie sogar die himmlischen Dinge in die Dinge der Sterblichen eingefügt und ihren Gesang mit Erfindungen und Fabeln angefüllt, damit dadurch jene Erhabenheit auf das Höchste, d. h. bis zur Bewunderung anwachse; [...]

38 In der Geschichtsschreibung werden nicht nur Ereignisse aneinandergereiht, sondern auch «die Ursachen [...] für die Unternehmung einer Handlung oder eines Krieges», « auch die Absichten, Meinungs- und Willensentscheidungen der Menschen » gehören in die Erzählung der Geschichte. Auch dürfen «Vorzeichen, Vogelschau, Weissagungen, Orakel, Gesichte[r], Opfer, endlich die Überläufer und Spionagen, ebenso die Gesandtschaften und die Aufträge an die Gesandten » nicht « übergangen » werden. (471) « Auch muss man vieles berühren, das jedoch nichts zu der unternommenen Geschichte hinzufügt, sondern durch seine von außen herangezogene Neuheit (novitate) Bewunderung (admirationem) und Lust (voluptatem) hervorbringt ». (475) 
der admiratio, sondern dient der Erklärung und Veranschaulichung der historischen Ereignisse (488).

Ein weiterer wesentlicher Unterschied ist die Reihenfolge (ordo), ${ }^{39}$ die für die Geschichte immer von der Chronologie bestimmt ist, ${ }^{40}$ in der Dichtung aber sehr viel freier gehandhabt werden kann.

Dichtung und Geschichte finden wieder zusammen in der Anerkennung der Natur als Vorbild der Mannigfaltigkeit, ${ }^{41}$ der Würde und der Anmut. Von ihr gilt es zu lernen, ihre Eigenschaften gilt es nachzuahmen. Wie schon bei Poliziano sprechen wir hier nicht von einer realistischen Abbildung der Natur, sondern in erster Linie von der Inspiration der (Vielfalt der) Natur, die zur Schöpfung anregt. Es handelt sich um die

[...] revendication du pouvoir démiurgique de l'écrivain qui détient la capacité de faire du monde ordinaire un objet admirable. ${ }^{42}$

Nach diesen theoretischen Bemerkungen schreitet Altilius fort zum Vergleich zwischen Vergil und Livius. Weilsich Livius' Geschichtsschreibung als durch und durch poetisch erweist - er « sich vor Augen die Größe der Dichter [zu halten schien], die Mannigfaltigkeit und die Beschreibungen der Orte und Völker, die Abschweifungen, Steigerungen, Umwege, den Schmuck und vor allem jenes Zierende, dem die Dichter vorzüglich zu dienen scheinen » (435) -, scheint Altilius' Ausgangsthese belegt, dass die Geschichtsschreibung «Dichtung in Prosa » genannt werden könne (432-433). Die Nähe von Geschichtsschreibung und Dichtung wird deutlich an folgendem Beispiel, in dem Livius die belagerte Stadt Thaumakoi nicht beschreibt, sondern eine «wunderbare» Ätiologie ihres Namens vorlegt: «dum nomen ipsum interpretari vult, locum illum historiae mirifice illustravit $[\ldots] »^{43}(480)$

Ubi ventum ad hanc urbem est, repente velut maris vasti, sic immensa panditur planities, ut subiectos campos terminare oculis haud facile queas; ab eo miraculo Thaumaci appellati, nec altitudine solum tuta urbs, sed quod saxo undique abscisso rupibus imposita est. ${ }^{44}(48 \mathrm{o}-482)$

39 Zur ordo vgl. auch 469.

40 Vgl. Cicero, De oratore, $2,63$.

41 Vgl. ebd., 2, 62.

42 Casanova-Robin, Étude introductive, S. CCL-CCLI.

43 Er «wollte [...] ihren Namen deuten und erhellte wunderbar jenen geschichtlichen Ort $[\ldots] »$.

44 Sobald man die Stadt erreichte, öffnete sich plötzlich wie eine Meeresfläche eine unermessliche Ebene, sodass man kaum mit den Augen die umliegenden Felder abgrenzen konnte. Wegen dieses Staunenswerten wurde die Stadt Thaumakoigenannt; sie war außerdem sicher 
Das Beispiel fügt sich optimal in Pontanos Poetik des Staunens ein: Die staunenswerte Wirkung, die die Stadt auf ihre Besucher ausübt, schlägt sich in deren Namen wieder. Dieser Konnex aus «miraculo» und erstaunlicher Sprache hat ihren Ort in der Dichtung, kann aber auch die Geschichtsschreibung bereichern. So kann auch der Geschichtsschreiber sich durch sein Ingenium («scriptoris ingenium », 485) auszeichnen, wenn er sein Augenmerk auf «[die] Erweiterung und [die] Verherrlichung» sowie den «Reichtum im Sprechen » (485) richtet.

Der Dialog plädiert für eine „engagierte“ Geschichtsschreibung. Der Schreibende «muss selbst in die Rolle des Richters schlüpfen, um zu loben, zu verurteilen, zu bewundern, herabzusetzen und sich zu erbarmen » (485). Der Geschichtsschreiber zeigt Gefühle, er lacht und weint. Die Geschichte ist die «Lehrmeisterin des menschlichen Lebens und der menschlichen Dinge » und als solche soll sie in einem didaktisch-pädagogischen Gestus verfasst sein. Die Rede des Altilius endet in einer Lobpreisung der Geschichtsschreibung, da sie uns aufzeigt, «welche Menschen zuerst Gott erkannten, [...] welche Männer die Gesetze festlegten, die Geheimnisse der Natur aufdeckten, die Künste erfanden und die Vorschriften zum Leben überlieferten » (493). So sind die Menschen von den Wäldern in die Städte gekommen, haben ihre Wildheit in Menschlichkeit und Gerechtigkeit umgewandelt und sich so « den Göttern nicht nur angenehm, sondern ganz ähnlich [ge]macht» (493).

Zusammengefasst lässt sich sagen, dass Dichtung und Geschichte sich dann nahe sind, wenn die Geschichte sich der aussergewöhnlichen Sprache und der Inhalte der Dichtung bedient, um historische Geschehnisse zu veranschaulichen..$^{45}$ Die Historiographie ist der veritas verpflichtet und bindet die

nicht nur wegen ihrer Höhe, sondern weil sie auf einem nach allen Seiten abschüssigen Felsen wie auf Klippen lag.

45 Die Veranschaulichung wird schon von Polybios und Strabon als zentrales Moment der Geschichtsschreibung und der Dichtung genannt. Polybios versucht, die Dichtung Homers der Geschichtsschreibung zuzuordnen: «In order to demonstrate the truthfulness of Homer, Polybius writes: ,Now the end aimed at by history is truth, and so we find the poet in the Catalogue of Ships mentioning the peculiar features of each place, calling one town ,rocky', another ,on the border', another ,with many doves', another ,by the sea; and the end aimed at by disposition is vividness, as in his battles scenes, while the aim of myth is to please or to astonish .... In the opposition between history and myth, therefore, Homer stands firmly on the side of history (and truth), because the aim (telos) of his poetry is ,vividness“ (enargheian). "Siehe CARlo Ginzburg, Ekphrasis and Quotation, in: Tijdschrift Voor Filosofie 50 (1988), S. 6. Ginzburg zitiert auch PseudoLongin, Quintilian und Cicero: Alle drei definieren die Veranschaulichung als zentrales Mittel der Geschichtsschreibung (ebd., S. 7). 
admiratio zu diesem Zweck ein. ${ }^{46}$ Für die Dichtung hingegen ist die admiratio das höchste Ziel; ihr sind alle Mittel - Fiktion, Vielfalt, Aussergewöhnlichkeit und Herrlichkeit - untergeordnet.

\subsubsection{Dichtung und Rhetorik: Gut und angemessen zur Bewunderung sprechen}

Nam, te obsecro per Musas ipsas perque tantopere a nostro cultam Sene Uraniam, quid nisi admiratio, quid, inquam, nisi una et sola admiratio quaeritur ex magnificis illis et maxime numerosis verbis dictisque $[\ldots]^{47}(5 \mathrm{OO})$

Die eigentliche Poetik des Actius wird in Abgrenzung zur Rhetorik entwickelt. Auch mit dieser hat die Dichtung bestimmte Redeweisen gemein, beispielsweise die Lobrede, aber während der Redner diese ernsthaft und würdevoll zu gestalten hat, gilt es für den Dichter, grossartig und aussergewöhnlich sein $(499) \cdot{ }^{48}$

Neque enim gravitas comparandae admirationi satis est sola, ni magnificentia accesserit excellentiaque et verborum et rerum $[\ldots]^{49}(498)$

Der Redner kann hie und da Grossartiges und Aussergewöhnliches einflechten, die Sprache des Dichters aber muss durchwegs « peculiare » sein $(498) .{ }^{50}$

Sowohl Dichter als auch Redner wollen das Publikum bewegen («movere et flectere», 498), wiederum aber unterscheidet sich die Absicht der beiden Redeformen. Zielt der Redner darauf, den Richter zu überzeugen und den Prozesssieg davonzutragen, will der Dichter Staunen und Bewunderung hervorrufen und mit Ehre und Hochachtung bedacht werden. Die Ausrichtung der jeweiligen Texte wird durch das Publikum bestimmt: Die Rede richtet sich an Richter und Personen im Gerichtssaal. Die Dichtung ist an die Dichter gerichtet sowie an Personen, die in den litterae gebildet sind:

46 TAteO, La poetica, S. 29 o.

47 Denn - ich beschwöre dich bei den Musen und bei der von unserem Senex so verehrten Urania - was, wenn nicht die Bewunderung, was, sage ich, wenn nicht allein und einzig die Bewunderung wird in jenen großartigen und rhythmischen Worten [der Dichtung] gesucht?

48 Zur Grossartigkeit der Dichtung vgl. ebenfalls die Seiten 506-508.

49 Denn die Ernsthaftigkeit genügt nicht allein, um Bewunderung zu verschaffen, wenn nicht eine Großartigkeit und Außergewöhnlichkeit von Worten und Sachen hinzukommt $[\ldots]$

50 Der Übersetzer übersetzt « peculiare » mit « eigentümlich». Ich würde vom Kontext her eher mit „ausserordentlich“ übersetzen. 
Nec vero audientem aut legentem eum nos intelligi volumus cui sit admirationi Bavius aut Maximianus, sed cui magnam quoque mentem Delius inspiraverit vates; vix enim de bono poeta, nisi et ipse auditor bonus poeta fuerit, iudicare recte potest. ${ }^{51}(498)$

Um den Text auf das Dichterpublikum auszurichten, gilt es für den Dichter, die verschiedenen Phasen der Entstehung - inventio, dispositio und elocutio - in den Dienst der admiratio zu stellen.

videte, obsecro, quibus veritatem commentis concinnaverit, quo admirabiliora cuncta redderet. ${ }^{52}(504)$

Comparationes quoque, quibus frequentissime utuntur, non magis ad docendum atque illustrandum pertinent quam ad movendam admirationem. ${ }^{53}$ (504)

Verba autem [...] poetae non solum simul compangunt aut ea novant, [...] verum ea transferunt, nec verba tantum, sed orationem persaepe omnem. [...] Nec vero tenorem hunc comparandae admirationis in gravioribus ac seriis tantum servant rebus, verum in iis quoque in quibus lectorum atque auditorum delectatio voluptasque sola quaeritur $[\ldots]^{54}\left(5^{\mathrm{O} 4}-506\right)$

Die Welt der Dichtung entsteht durch starke und bewegende Bilder - Vergleiche und Metaphern. Vergleiche werden häufig eingesetzt, da sie das Gesagte durch ungewohnte Verbindungen intensivieren und damit gleichzeitig belehren und erstaunen. Metaphern und Metonymien dienen als Stilmittel, um Gewöhnliches auf Ungewöhnliches, Fiktives, zu übertragen. Nicht nur die Übertragung, auch die Verwandlung («transferunt») wird als Mittel genannt, um admiratio zu erzeugen. Wahrhafte Dichter verfügen über die Fähigkeit, Texten ganzheitlich einen übertragenen Sinn zu verleihen. Sie schaffen neue Welten, die von der Realität und der Natur abweichen und in der Übertreibung und

51 Aber wir wollen unter Hörer und Leser nicht den verstanden wissen, dem Bavius oder Maximianus zur Bewunderung gereicht, sondern dem der Seher von Delos eine große Vernunft eingehaucht hat; denn der Hörer kann kaum über einen guten Dichter richtig urteilen, wenn er nicht auch selbst ein guter Dichter ist. // Vgl. auch S. 500.

$5^{2}$ Seht nur, ich bitte euch, mit welchen Einfällen er [Vergil] die Wahrheit kunstfertig zusammenbaute, um alles noch bewundernswerter zu machen.

53 Auch die Vergleiche, die sie am häufigsten benutzen, erstrecken sich ebenso sehr auf das Belehren und die Erleuchtung wie auf das Erregen von Bewunderung.

54 Die Dichter aber [...] fügen nicht nur gleichzeitig Wörter zusammen oder schaffen sie neu, [...] sondern sie übertragen sie, und zwar nicht nur die Wörter, sondern sehr oft die ganze Rede. [...] Sie bewahren aber diese Eigenart zur Erregung der Bewunderung nicht nur bei schwerwiegenden und ernsthaften Dingen, sondern auch bei solchen, worin allein das Entzücken und Vergnügen der Leser und Zuhörer gesucht wird [...] 
Ausschweifung («excessus») besonders stark auf die Zuhörer wirken (5०5). ${ }^{55}$ Das Oxymoron und die Hyperbel, bisweilen auch das Paradoxon oder die Katachrese, erweisen sich ebenfalls als wirkungsstarke Mittel zur Erzeugung von admiratio.

In der Dichtung ist jede Abweichung von Wahrheit und Realität dadurch legitimiert, dass sie zur Wirkung der admiratio beiträgt.

Itaque non verbis modo magnificis, sed rebus quoque et inventis excellenter et expressis admiratio a poetis quaeritur, ut, cum poetica sicut historia constet rebus ac verbis, his utrisque poeta ad admirationem conciliandam non utatur modo, verum etiam innitatur. Quamobrem, quod veritas praestare hoc sola minus posset, veritatem nunc inumbrant fictis faublosisque commentis, nunc ea comminiscuntur quae omnino abhorreant a vero atque a rerum natura $[\ldots]^{56}$ $(502)$

Die Betonung des Fiktionalen hängt mit den zentralen Eigenschaften von sublimitas und magnitudo zusammen, die Actius für jede Art von Dichtung als zwingende Eigenschaften definiert (506).

Fictio trägt zur sublimitas bei, wenn die menschliche durch die göttliche Sphäre angereichert wird. Diese sublimitas wiederum steigert die Wirkung des Staunens und der Bewunderung. ${ }^{57}$

Am Schluss des Dialogs leitet Actius her, weshalb die Dichtung als höchste aller Redeformen gilt: weil sie den Ursprung der Zivilisation und des Wissens darstellt und weil sie die erhabenste aller Redeformen ist. ${ }^{58}$ Am Anfang stand der Gesang in Versen, aus ihm sind alle anderen Redegattungen « entströmt » (509). Die Dichtung hat « als erste über Gott gehandelt», sie hat Gerechtigkeit und Tugend eingesetzt, sie hat die «Seelen der Frommen von der Erde in den

55 Als Beispiele werden unter anderem genannt: «praeruptus aquae mons (ein jähes Wassergebirge) »; « vastos tollunt ad sidera fluctus (sie heben die weiten Wogen bis zu den Sternen hinauf)» (506-507).

56 Daher wird die Bewunderung von den Dichtern nicht nur durch großartige Worte, sondern auch durch hervorragend erfundene und ausgedrückte Sachen gesucht, sodass da die Dichtung wie die Geschichte aus Sachen und Worten besteht, der Dichter diese beiden zur Bereitung der Bewunderung nicht nur gebraucht, sondern sich sogar darauf stützt. Weil die Wahrheit allein dies weniger zu leisten vermöchte, deuten sie die Wahrheit bald durch erdichtete und märchenhafte Erfindungen an, bald erdichten sie etwas, was überhaupt vom Wahren und der Natur der Dinge zurückschreckt [...] // Vgl. dazu Denizot, „Comme un souci“, S. 74 .

57 Der Begriff des „Sublimen“ wurde insbesondere von Pseudo-Longin geprägt. Klaus Ley argumentiert dafür, dass Pontano die Texte Pseudo-Longins gekannt haben dürfte. Siehe KLAUs Ley, Longin - von Bessarion zu Boileau. Wirkungsmomente der „Schrift über das Erhabene" in der frühen Neuzeit, Berlin 2013.

58 Denizot, „Comme un souci“, S. 73. Vgl. dazu ebenfalls Pontano, Dialoge, S. 498. 
Himmel », « die Seelen der Unfrommen in den Tartarus » versetzt und sie hat die Menschen zivilisiert. Sie ist damit Essenz und Ursprung unserer Zivilisation und Kern dessen, was uns als Menschen und als Gesellschaft ausmacht. Zudem erhielten von Homer « die Philosophen, die Physiker und die Redner die Vorschriften für ihr Fach und nahmen seit ihm ihren Anfang » (509). Weil die Gelehrten die Dichtung Homers bewundert und bestaunt haben, haben sie sie nachgeahmt und aus ihr neue Redeformen entwickelt (508). In diesem Sinne sind die Bewunderung und das Staunen Initiationskräfte; sie stehen am Anfang der Dichtung und mit dieser am Anfang der Gesellschaft und des Wissens. ${ }^{59}$ Mit dieser Passage stellt Actius die Dichtung über die Geschichtsschreibung, der von Altilius die Vermittlung des Wissens attestiert wurde: Die Dichtung hat nicht zum Ziel, Wissen zu vermitteln, steht aber dennoch am Ursprung von diesem.

\subsection{Pontanos literarisches Werk}

Pontanos literarisches Werk zeichnet sich aus durch eine überaus originelle Verbindung verschiedener Genres, Inhalte und Stile sowie durch die fabelhafte Atmosphäre, in der Reales ${ }^{60}$ und Mythisches, Traditionelles und Innovatives aufs Engste ineinander- und übereinandergelegt werden. Zentrale Mittel sind die Mythologisierung, die Personifikation sowie die Metamorphose: Die Landschaft Kampaniens und die literarische Tradition der antiken Literatur, insbesondere die bukolische Dichtung, sind das Terrain für die literarische Fantasie und Fiktion Pontanos.

En effet, dès sa première rencontre avec ce recueil, le lecteur est frappé par le caractère exceptionnel de l'inventio pontanienne. Cette créativité illustre du reste parfaitement la réflexion sur l'essence même de la poésie menée par Pontano depuis le dialogue Antonius (1487-1488), où il montre notamment que la grandeur d'Homère, premier des poètes, n'est pas redevable de l'imitation puisqu'il est le premier des poètes, mais tient précisément à la création. ${ }^{61}$

La mitologia pontaniana, infatti, non ha quasi nulla a vedere con quella classicamente tradizionale: la fantasia e l'anima del poeta la creano con gli elementi plastici di una realtà panoramica contemporanea, che di quella classica

59 Tateo, La poetica, S. 356. Siehe ebenfalls Marc Deramaix, Excellentia et admiratio dans l'Actius de Giovanni Pontano. Une poétique et une esthétique de la perfection, in: Mélanges de l'école française de Rome 99 (1987), S. 210.

60 Das „Reale“ beinhaltet insbesondere ländliche und lokale Gegebenheiten Neapels. Meist schwingt eine bukolische Komponente mit; die Apotheose des ländlichen Lebens und der Pflanzen ist Bestandteil aller Werke Pontanos.

61 Casanova-Robin, Étude introductive, S. CXLI. 
non ha la maestosità superumana ma non ha neppure la marmorea freddezza; si è umanizzata, è divenuta, nelle figurazioni e fin anche nei nomi, espressione di vita naturale, palpitante di verità attuale, profumata di schietta italianità, molle, armoniosa, suggestiva. ${ }^{62}$

Merkmal von Pontanos moderner, landschaftlich verankerter Mythologie ist deren Sensualität, die geradezu darauf drängt, auditive, visuelle und olfaktorische Eindrücke zu einem intensiven Gesamtgepräge zu verdichten. ${ }^{63}$

\subsubsection{Lepidina}

Die Vielfältigkeit und Originalität von Pontanos literarischem Werk versuche ich anhand der Ekloge ${ }^{64}$ Lepidina aufzuzeigen - mit einzelnen Querverweisen auf weitere poetische Texte. ${ }^{65}$ Lepidina ist in der heutigen Werkform die erste von sechs Eklogen, obwohl sie als letzte 1496 entstand. Die Eklogen entstanden in jahrelanger Arbeit von 1463 bis zu Pontanos Tod. Das Manuskript, das Pontano 1503 Aldus Manutius vorlegte, ist heute nicht mehr erhalten. Das Werk erschien schliesslich erst nach Pontanos Tod in einer venezianischen (Aldus Manutius) und einer neapolitanischen Ausgabe (Pietro Summonte); eine vom Autor abgesegnete Anordnung kann nur für die ersten vier Eklogen der heutigen Anordnung angenommen werden, die zwei weiteren in der neapolitanischen Erstausgabe enthaltenen Eklogen wurden von Pontanos Freund und Verleger Pietro Summonte hinzugefügt und differieren metrisch, inhaltlich und stilistisch von den anderen vier Eklogen. ${ }^{66}$

62 GUSTARELLI, Introduzione, S. 13.

63 Casanova-Roвin, Étude introductive, S. XXX, ebenfalls CCLXV.

64 Obwohl nicht als Genre des hohen Stils eingestuft - nur der bescheidene und einfache Stil sei ihm angemessen -, hat das bukolische Gedicht im Mittelalter und der Frührenaissance neuen Aufschwung erlangt, der wohl in erster Linie der Bewunderung und Verehrung Vergils zu verdanken ist. Mit Petrarcas Eklogen hat das Genre eine Erweiterung und Erhöhung zugleich erfahren. Petrarca hat die symbolischen und allegorischen Komponenten betont und für das ländliche Gedicht einen elaborierten Stil eingeführt. Insbesondere hat er den Eklogen eine innerliche und autobiographische Note verliehen er hat den Widerstreit in seiner Seele, seine verzehrende Liebe nach Laura und seine Trauer über den Tod geliebter Personen in die Eklogen eingewoben. Die beiden letztgenannten Motive sind auch für Pontanos Dichtung zentral. Siehe CASANova-Robin, Étude introductive, S. XXXIV-XXXV.

65 Gustarelli, Introduzione, S. 15: « Di esse [delle Eclogae] la più vasta e interessante, la più ricca di elementi fantastici e di pregi poetici, è la prima, Lepidina, che ha la forma di una ampia rappresentazione scenica, piena di movimento e di colore, più che di un semplice poemetto.»

66 Casanova-Robin, Étude introductive, S. XLIII-XLV. Für die Editionsgeschichte vgl. ebenfalls: Carmela Vera Tufano, Le Eclogae di Giovanni Pontano, tesi di dottorato, Napoli 2009, S. 1-4. Online verfügbar unter http://www.fedoa.unina.it/8387/1/tufano carmela_23.pdf (Stand April 2021). 
Unter Pontano und Sannazaro florierten die Innovationen am klassischen Genre der bukolischen Dichtung, die zunehmend zum Genre des poetologischen Dialogs wurde. ${ }^{67}$

En effet, l'activité principale des bergers consiste à composer des chants, renvoyant en miroir une représentation d'un poète qui se tient à lécart du monde [...] Le genre bucolique devient ainsi le terrain privilégié d'une réflexion littéraire, esthétique et éthique, comme le lieu par excellence où le poète se met en scène $[\ldots]^{68}$

Die Ekloge ist aber nicht nur Ort der poetologischen Reflexion, sondern auch der poetologischen Vielfalt. Diese zeigt sich insbesondere in der Anreicherung des bukolischen Genres mit Elementen anderer Genres: In Lepidina webt Pontano das Epithalamium - das Hochzeitsgedicht -, ebenso aber auch elegische, epische, ätiologische und komische Aspekte ein. ${ }^{69}$ Künstlerische Freiheit und Vielfalt erweisen sich als zentrale Eigenschaften des Dichters und der Dichtung. ${ }^{70}$

Der künstlerische Einfallsreichtum zeigt sich allen voran im Hauptmerkmal von Lepidina: der Verwandlung der Landschaft in und um Neapel in Götter und Göttinnen, Nymphen, Nereiden, Dryaden und Oreaden, aber auch in unliebsame, borstige Riesen - Gustarelli spricht von einer «fantasmagorica rassegna » personifizierter Gestalten. ${ }^{71}$ Neapel und die umliegende Gegend werden zu einem « paysage enchanté »: ${ }^{72}$

Le paysage offre ainsi plusieurs strates de lecture: lieu d'identification du genre qui permet l'inscription dans la filiation virgilienne, métaphore d'un «moi» intime autant que poétique et en outre élément central d'une géographie littéraire qui reflète l'ambition d'un foyer humaniste soucieux de revendiquer l'héritage antique et sa fécondité créatrice, manifeste dans l'invention de mythes étiologiques topographiques. Dans le territoire napolitain, ainsi recomposé, et

67 Casanova-Robin, Étude introductive, S. XXIX.

68 Ebd., S. XXXI.

69 Ebd., S. XLII: «Les théoriciens témoignent ainsi de la difficulté à enserrer cette poésie dans un cadre stricte, d'autant qu'elle procède, dès son origine virgilienne, d'une esthétique du mélange, au gré d'une imitatio disputant avec l'inventio. » Zur Vielfalt der literarischen Formen sowie ihrer Quellen siehe LEONARD W. Grant, An Eclogue of Giovanni Pontano, in: Philological Quarterly 36 (1957), S. 78-8o. Siehe ebenfalls Tufano, Le Eclogae, S. 23-26.

70 Ferraù, Pontano critico, S. 3 .

71 Gustarelli, Introduzione, S. 16. Die Präsenz von Göttern, Nymphen, Oreaden ist ungewöhnlich für das Genre der Ekloge, das normalerweise nur von Hirtenfiguren bevölkert wird. Siehe Tufano, Le Eclogae, S. 23.

72 Casanova-Robin, Étude introductive, S. CXLIII, CXLIV. 
peuplé de créatures imaginaires, le poète ravive des archétypes mythologiques et littéraires, où résonnent les échos virgiliens et statiens prioritairement qui convoquent la culture grecque par la médiatisation de la culture latine pour devenir un espace dédié à une féconde inspiration poétique. ${ }^{73}$

Leitend für die Erkundung der literarischen Landschaft ist die Lenkung des Leserblickes, der von der Küste Neapels ins Innere der Region geführt wird. Von den Nereiden, die die Inseln vor Neapel darstellen, leitet der Gesang über die personifizierten und feminisierten «meravigliose contrade neapoletane » bis hin zu den Riesen und Nymphen der Vulkan- und Berggegend. ${ }^{74}$ Stets wird zwischen realer und imaginärer Welt eine Spannung erzeugt, die den Leser an Gewohntes erinnert; gleichzeitig erscheint das Gewohnte durch überraschende Bilder aber neu und ungewohnt. ${ }^{75}$

Or, le mirabile tient précisement dans cette tension entre le «proche et le lointain , le familier et l'extraordinaire $[\ldots]^{76}$

Diese Spannung wird dadurch untermauert, dass der Blick des Lesers von den sprechenden Figuren auf das Ausserordentliche gelenkt wird. Das Hirtenpaar und weitere Figuren berichten über Gesehenes, Gehörtes und Erinnertes. Auf dieser vermittelnden Ebene entsteht die Möglichkeit, die Wahrnehmung der Leser durch entsprechende Kommentare zu steuern. Insbesondere können Objekte des Staunens als solche positioniert und markiert werden. ${ }^{77}$

PlanuRis.

Assideo, Lepidina, et poma et pocula sumam:

Mox tibi et heroas referam summosque Oriarchas,

Quos mirere, soror, simul et uereare superbos. ${ }^{78}$ (Lepidina, V, Vv. 41-43)

73 Casanova-Robin, Étude introductive, S. XLI.

74 Gustarelli, Introduzione, S. 16; CASANOVA-Robin, Étude introductive, S. CXLVII.

75 Casanova-Robin, Étude introductive, S. CLII-CLIII, ebenso CCXLII-CCXLIII: «Or pour rendre la matière admirable, capable, d'emplir les oreilles, les yeux et l'esprit d'admiration' [...], il est tout d'abord nécessaire d'ouvrir la matière poétique à une dimension qui dépasse celle de la nature, en laissant libre cours à sa phantasia.» Die von Casanova-Robin zitierte Stelle referenziert auf den Dialog Antonius: « et aures et oculos et animum admiratione [...] implet. » Siehe Pontano, Dialoge, S. 182.

76 Casanova-Robin, Étude introductive, S. CCXLVI.

77 Ebd., S. CCLII.

78 Ich zitiere aus der bereits genannten Ausgabe von Hélène Casanova-Robin: Pontano, Églogues / Eclogae. Die kritische Ausgabe von Casanova-Robin basiert auf der editio princeps Aldina. Die Übersetzungen aus den Eclogae stammen von der Autorin (A.E.) in Anlehnung an die Übersetzung ins Französische von Hélène Casanova-Robin und jene ins Italienische von Andrea Gustarelli: «Planuris. Ich setze mich zu dir, Lepidina, 
Erstaunliches wird nicht nur von den Figuren und Helden erzählt - die allesamt nicht der klassischen, sondern der humanistischen Mythologie Pontanos entstammen -, sondern insbesondere auch vom poetischen Gesang. Dem Staunen über die Dichtung begegnen wir in allen Eklogen, so auch in Acon, wobei wiederum der orphische Gesang und dessen Wirkung Pate gestanden haben dürften:

\author{
SAliuncus. \\ Et nostri, Petasille, greges sensere canentem \\ In siluis Meliseon, ${ }^{79}$ adesaque saxa sonorem \\ Dum referunt, tacitae cantum stupuere Napaeae; \\ Et - mirum - fessae uocem tenuere cicadae \\ Prostrataeque solo iacuere ad carmina uaccae, \\ Oblitae cytisum pecudes, satureia capellae. ${ }^{80}$ (Acon, Vv. 6o-65)
}

Neben der Dichtung gesellen sich die schönen und erotischen Frauenkörper zu den Objekten des Staunens. So berichten beispielsweise Syncerius und Zephyreus in Maeon über ihr Staunen beim Anblick der Napaien:

\title{
SYNCERIUS.
}

Vidi ego picta manu selectaque frage legentem, Innuit et mihi, serta deus dum stringit in umbra: Hic tibi tum femur hirsutum saetosaque menta Obstupui atque oculos fruticoso in margine fixi.

\section{ZEPHYREUS.}

Vidit me dum poma lego arrisitque legenti, Et dixit mihi Nais: «Amant et poma Napaeae». His ego tum impleuique sinum obstupuique papillas Pectora dum limis oculis et colla pererro. ${ }^{81}$ (Maeon, Vv. 39-46)

und werde die Früchte und die Becher nehmen: / Danach werde ich dir von den Helden und den höchsten Orearchen berichten, / deren stolzes Antlitz du, Schwester, zugleich bestaunen und fürchten wirst. »

79 Meliseus wird als Alter Ego Pontanos bezeichnet. Die zweite Ekloge ist nach ihm benannt. Meliseus ist ein Hirte, der verzweifelt den Tod seiner Frau besingt. Ein grosser Teil von Pontanos dichterischem Werk sind Elegien und Nenien auf den Tod seiner Frau und seines Sohnes. Siehe Casanova-Robin, Étude introductive, S. CCLII; ebenso Tufano, Le Eclogae, S. 275.

8o Saliuncus. Auch unsere Herden, Petasillus, haben Meliseus in den Wäldern / singen gehört, und während der Klang von den festen Felsen / wiedergegeben wurde, erstaunten die Napeen schweigend vor seinem Gesang; / und die müden Zikaden (oh Wunder!) hielten ihre Stimmen zurück, / und die überwältigten Kühe legten sich hin beim Klang der Lieder, / und die Schafe vergassen das Klee, die Ziegen das Bohnenkraut.

81 SNYCERIUS. Ich sah, wie sie mit ihren Händen farbenprächtige, erlesene Erdbeeren sammelte, / der Gott winkte mir zu, während er im Schatten Girlanden schnürte: / Beim Anblick seines haarigen Oberschenkels und seines borstigen Kinns / erstaunte ich und 
Von den genannten Eigenheiten - poetologische Reflexion, mythologisierte Topographie, Spannung zwischen Realität und Fiktion sowie staunende Vermittlung des Wahrgenommenen - und Objekten ausgehend, wenden wir uns nun den einzelnen Teilen von Lepidina zu.

Die Ekloge setzt sich zusammen aus einem Prolog und sieben pompis (Aufzügen), insgesamt zählt das Gedicht 821 Verse. ${ }^{82}$ Die Ekloge handelt vom Aufzug zur Hochzeit der Parthenope ${ }^{83}$ - der Sirene, die Neapel symbolisiert - und des Sebethus - des Flusses und Flussgottes, der durch Neapel fliesst. Weder Parthenope noch Sebethus entstammen der klassisch bukolischen Tradition, Pontano jedoch integriert sie nahtlos in diese und lässt sie von einem frisch vermählten Hirtenpaar - Lepidina und Macron ${ }^{84}$ - beschreiben. ${ }^{85}$

Macron und Lepidina sind auf dem Weg, dem mythischen Paar ihre Hochzeitsgaben zu überbringen. Da Lepidina schwanger und zudem schwer beladen ist, machen sie Halt im Schatten eines idyllischen Wäldchens. ${ }^{86}$ Von

fixierte meine Augen auf den Horizont voller Büsche und Zweige. / Zephyreus. Sie sah mich, als ich Äpfel auflas und lächelte über meine Ernte / und sagte zu mir: «Auch die Napeen mögen Äpfel. » / Also füllte ich ihren Schoss mit Äpfeln und erstaunte beim Anblick ihrer Brüste / und liess meinen Blick auf ihrer Brust und ihrem Hals ruhen.

82 Die Länge des Gedichts ist aussergewöhnlich und passte eher zu einem Epos als zu einer Ekloge. Siehe Tufano, Le Eclogae, S. 23.

83 Casanova-Robin, Étude introductive, S. 168: «Parthénopé est l'hérö̈ne éponyme de la ville de Naples. La tradition rapporte qu'elle était originellement une sirène qui se jeta dans la mer par dépit après sa rencontre malheureuse avec Ulisse; son corps échoua sur le rivage campanien, là où fut fondée la fameuse cité. Elle est ici la figure allégorique de Naples, incarnation des plus hautes qualités de beauté et de vertu. » // Einige Kritiker sehen in Parthenope und der Mythologisierung Neapels und Kampaniens einen politischen Akt im Sinne einer Anknüpfung an die antiken Ursprünge der Stadt zur Stärkung der gegenwärtigen Situation. Parthenope wurde am Hof der Aragonesen auf vielfältige Weise zur Inszenierung und Anbindung der königlichen Macht eingesetzt. Die Vermutung eines politischen Zwecks scheint mir durchaus plausibel, auch wenn der Text - weder wörtlich noch allegorisch - politische Anspielungen macht. Siehe TUFANO, Le Eclogae, S. 29-30.

84 Lepidina kommt von lat. lepidus („niedlich, zierlich, allerliebst, prächtig, liebenswürdig, anmutig, gefällig, heiter“, ebenso „witzig“), Macron geht etymologisch auf gr. "gross, ernst, anspruchsvoll“ zurück. Tufano schlägt vor, Lepidina die Genres der Ekloge und des Epithalamiums, Macron das Epos zuzuschlagen, nennt aber selbst, dass sich von den Figuren her, so wie sie im Text konzipiert sind, eine solche Zuordnung nicht herleiten lässt. Auf jeden Fall verbinden sich durch die Heirat der beiden das Lateinische und das Griechische. Siehe Tufano, Le Eclogae, S. 32.

85 Casanova-Robin, Étude introductive, S. XLVI. Grant hebt hervor, dass es eher ungewöhnlich ist, als Protagonistenpaar ein verheiratetes Paar und nicht Verehrer und Angebetete zu wählen. Diese Wahl beruht höchstwahrscheinlich auf Pontanos Konzeption der Liebe, deren Vollendung in der Ehe er in De amore coniugale dargelegt hat. Siehe Grant, $A n$ Eclogue, S. 79 .

GUSTARELLI, Introduzione, S. 16 . 
dort aus beobachten sie den vorbeiziehenden Hochzeitsaufzug. Musikalisch gesprochen ist der grösste Teil der Ekloge als Duo - die typische Form des Hirten- sowie des Hochzeitsgedichts - oder als Trio komponiert, ein Solo findet sich im dritten Aufzug (Triton), der letzte Aufzug ist symphonisch aufgebaut. ${ }^{87}$ Es gibt keinen beschreibenden Erzähler; der Text wird durch die Äusserungen der zuschauenden Figuren, insbesondere von Macron und Lepidina, strukturiert. ${ }^{88}$

Im Prolog treten die beiden frisch Vermählten Macron und Lepidina auf. Sie lassen ihre erste Begegnung in sinnlicher Schilderung Revue passieren, gleichzeitig führen sie auf panegyrische Weise die Figur der Parthenope ein. Unter anderem wird die kraftvolle Wirkung der Sirene auf ihr Umfeld beschrieben: ${ }^{89}$
LEPIDINA.
Magnetem gerit illa oculis stellamque supremam:
Venerit ad litus, trahit ad sua lumina pisces
Iuerit in siluas, trahit ad spectacula ceruos,
Illicet indomiti surgunt ad proelia tauri;
Verterit illa oculos in quem iuuenemue senemue,
Ille perit: miseris haec crescit amantibus error. ${ }^{90}$ (Prolog, Vv. 42-47)

Zuerst wird der Fokus auf ihre leuchtenden Augen gelegt: Wie Magnete ziehen diese im Meer die Fische, in den Wäldern die Hirsche an, sie bändigen ungezähmte Bullen. Wer auf Parthenope seine Augen richtet («verterit [...] oculos»), ist verloren. Von den Augen geht der Bericht weiter zum Gesang, dem eine ebenso mächtige Wirkung nachgesagt wird.

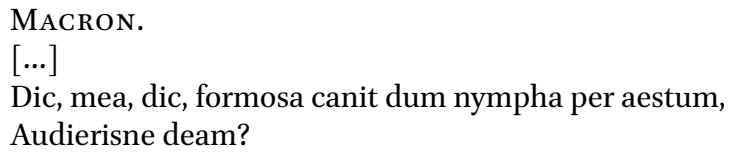

87 Casanova-Robin, Étude introductive, S. CCLXVIII. Grant erkennt in Lepidina dramatische Strukturen und hält es für möglich, dass die Ekloge mit Schauspielern al fresco aufgeführt wurde. Zu Recht weist er zudem auf die gekonnte Darstellung des Spiels im Spiel hin. Siehe Grant, An Eclogue, S. 8o.

88 Tufano, Le Eclogae, S. 24.

89 Grant, An Eclogue, S. 8 o.

9o LEPIDINA. In ihren Augen trägt sie einen Magnetstein, den höchsten aller Sterne: / Wenn sie an den Strand kommt, zieht sie mit ihren Augen die Fische an; / wenn sie in den Wald geht, bringt sie die Hirschen dazu, ihrem Schauspiel beizuwohnen, / sofort erheben sich die ungezügelten Stiere zum Kampf; / auf wen auch immer sie ihren Blick richtet, auf Junge oder Alte, / ist verloren: Und sie steigert den Liebeswahn der unglücklichen Liebenden. 


\section{LEPIDINA.}

Ad saepem tum forte latebam:

Cum canere inciperet, atrox hic dente pilaster

Latrat; ibi ipsa fuga saepem insidiasque reliqui.

Inuidia (sic Nicla refert) philomela recessit;

Ad circum attonitae stupuere ad carmina nymphae.

Ipsa quidem canit (at uenti posuere silentes

Strataque pacati requierunt murmura ponti):

« Exoptat messemque sator frugemque colonus,

uer ales, carum uirgo desponsa maritum;

uitis in arboribus, hederae pro rupibus altis,

coniugis in cupidis gaudet noua nupta lacertis;

irriguum sitiunt fontem sata, pabula rorem,

nupta sitit socii lusus et gaudia lecti ».91 (Prolog, Vv. 67-80)

Wenn Parthenope die Fruchtbarkeit der Natur und die Vereinigung der Liebenden besingt, erblasst die Nachtigall vor Neid, erstarren die Nymphen voller Staunen («attonitae stupuere ad carmina nymphae »), verstummen die Winde und das Rauschen des Meeres. Lepidina ist Zeugin des wundersamen Gesangs, da sie diesem von einem Versteck aus heimlich lauscht. Hat Orpheus den Gesang der Sirenen mit seiner Leier und seinem Gesang übertönt, ${ }^{92}$ macht die Parthenope ihm an dieser Stelle Konkurrenz. Dennoch bleibt sie trotz ihrer zentralen Rolle eine marginale und entfernte Figur; ausser dem zitierten Gesang über das Verlangen der Natur und der Liebenden finden sich keine weiteren Äusserungen von ihr.

Der erste Aufzug ist als Epithalamium orchestriert. In abwechselnden, kurzen Passagen besingen Chöre bestehend aus Männern und Frauen die bevorstehende Vereinigung des Hochzeitspaares.

91 Macron. [...] Sag mir, meine Liebe, sag mir, wenn die schöne Nymphe im heissen Sommer singt, / hast du die Göttliche jemals gehört? / LEPIDINA. Ich stand zufällig hinter einem Gebüsch, / als sie zu singen begann, fing auch ein grässlicher Köter an / zu bellen; da verliess ich sofort mein Versteck im Gebüsch. / Aus Neid habe Philomela sich zurückgezogen (so berichtet es Nicla); / aber ringsherum staunten die begeisterten Nymphen über ihren Gesang. / Sie singt, und schweigend legen sich die Winde, / und das ausgedehnte Gemurmel der befriedeten Wellen zerstreut sich: / « Der Sämann wünscht sich die Ernte herbei, der Bauer die Frucht, / der Vogel den Frühling, die Braut den treuen Bräutigam ; / die Rebe schlingt sich gern um den Baum, das Efeu an den hohen Felsen, / die Frischvermählte liebt es in den verlangenden Armen des Bräutigams; / die Saat dürstet es nach wässernden Quellen, die Weiden nach Tau, / die Braut sehnt sich nach den Spielereien des Bräutigams und den Freuden des Ehebetts. »

92 Siehe Apollonios Rhodios, Argonautica, IV, Vv. 903-919, beispielsweise in der Ausgabe von William H. Race. 
Im zweiten Aufzug besingen Macron und Lepidina die vorbeiziehenden Nereiden. Diese sind keine filigranen Meerfrauen mit fliessenden Formen, sondern riesige und massige Figuren, die als Allegorien die Küstenregionen und Inseln, die um und vor Neapel liegen, darstellen. ${ }^{93}$ Am Ende des Aufzugs berichtet Lepidina von ihrer Begegnung mit Capri, an die sie eine bleibende Erinnerung bewahrt:

\author{
LEPIDINA. \\ Illam [Caprei maris heroine] ego, dum Capreas peterem cum matre, sedentem \\ Ad scopulum uidi. Famulae properare legentes \\ Ostrea et euulsas lapidoso e margine conchas; \\ Accepit dea me gremio et donauit echinis. \\ Obstupui ingentemque umero ingentemque lacertis \\ Atque utero et toto retinentem corpore formam. \\ Horrebant sed crura nigris et pectora saetis, \\ Purior Aequana cum sit nihil aut sit Amalphi, \\ Vtraque odoriferum spirent et pectore anethum. ${ }^{94}$ (II, Vv. 8o-88)
}

Die Inselnereide wird anhand visueller und olfaktorischer Eindrücke beschrieben. Staunen (und zugleich auch Schrecken) bereitet der grosse massige Körper, der dennoch eine eigentümliche Schönheit besitzt. Bleibend - auch für den Leser - ist der süssliche Duft nach Fenchel. Während die Erzählerin über den Körper der Inselnereide staunt, nimmt der Leser fasziniert die originelle Darstellung der Insel als schwarzhaarige Nymphe zur Kenntnis. Das Bild weist gewisse Ähnlichkeitsbezüge zur realen Insel auf, gleichzeitig wird Capri durch sonder- und wunderbare Elemente fantasievoll neu geformt.

Der dritte Aufzug ist fast vollständig ausgefüllt vom Hochzeitsgesang Tritons - er besingt die Hunderte von vorbeiziehenden Nymphen, Frauen und Mädchen, Diener und Dienerinnen, die Gottheiten der Meere und beschreibt

93 Die Nereiden heissen Pausylipe (Posilippo), Mergelline (Mergellina), Prochyte (Procida), Caprite (Capri), Sarnitis (Sarno), Resina, Hercli (Monte d'Echia), Aequana (Vico Equense) und Amalphis (Amalfi). Die griechische Schriftweise sowie die Aussprache sollen den griechischen Ursprung Neapels vor Augen führen. Siehe Casanova-Robin, Étude introductive, S. 174.

94 LEPIDINA. Ich habe sie gesehen, als ich mit meiner Mutter Capri besucht habe, / sitzend auf einem Stein. Ihre Dienerinnen sammelten eilig / Muscheln und Austern von der steinigen Küste ; / Die Göttin nahm mich in ihren Schoss und offerierte mir Seeigel. / Ich erstaunte beim Anblick ihrer gewaltigen Schultern und ihrer muskulösen Arme, / während ihr Unterleib und der Rest ihres Körpers schön proportioniert waren. / Aber die schwarzen Haare an ihren Beinen und auf ihrer Brust schauderten mich / und sie ist nicht reiner als Equana oder Amalfi, / beide verbreiten aus ihrer Brust den betörenden Duft von süssem Fenchel. 
zum einen deren feierlich geschmückte Aufmachung, zum anderen die Geschenke, die sie für das Hochzeitspaar mitführen. Der Gesang mündet in Glückwünschen für das Paar und einer Aufforderung zum Tanz an die ganze Gesellschaft. Im Anschluss folgt eine kurze Passage, die hervorragend die Ambivalenz der Figuren, wie sie für Pontano typisch ist, illustriert. Nachdem Triton als wohlwollender, lobender Gott aufgetreten ist, bezeichnet ihn Lepidina als gerissenen Jüngling («iuvenis malus», V. 37), weil er sie beim Baden beobachtete und ihr folgte, obwohl sie ihn zurückgewiesen hatte. ${ }^{95}$ Lepidina wird durch ihren Bericht über das Begehren des Meeresgottes mythologisiert und erhöht. Ihr kommt eine ähnliche Rolle zu wie den vielen unwillentlich von rasenden Liebhabern verfolgten weiblichen Figuren der Mythologie (z. B. Europa, Echo, Daphne). Die kreative Anreicherung der Figuren mit mythischem Material sowie ihr Changieren zwischen bukolischer und mythischer Welt sind Kennzeichen von Pontanos poetischem Verfahren und stehen im Dienst der admiratio. ${ }^{96}$

Im vierten Aufzug treten originell und teilweise komisch die puellae der neapolitanischen Vorstadtviertel auf und präsentieren ihre kulinarischen Spezialitäten. Die puellae werden aufgrund verschiedener Auslöser bestaunt: wegen ihrer Arbeit, ihrer Schönheit oder aber ihres Gesangs.

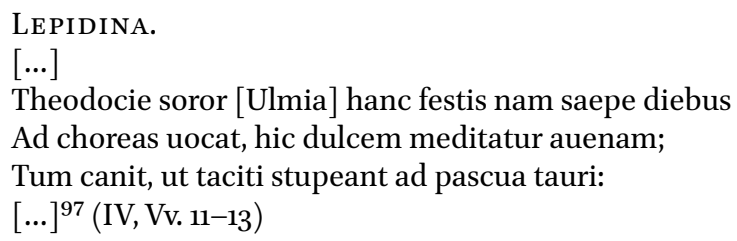

Ulmia ist «hochgelobt» («tantum laudata », V. 8) für ihre Torten und Biskuits, die Liebhaber erglühen in verzehrendem «ardor» (V. 10). Eine wundersame und animalische Kraft entspringt ihrem Gesang. Die Stadtgöttin ist stolz auf die Talente und Schönheiten in ihren Vierteln:

95 Diese Vielschichtigkeit der Figuren zeigt sich an vielen Stellen. Im Prolog beispielsweise wird Parthenope erst als vortreffliche und tugendhafte Nymphe verehrt, dann aber wird davon berichtet, wie sie die Männer skrupellos in ihren Bann zieht.

96 Vgl. Pontano, Dialoge, S. 423, 504, 506.

97 Lepidina. Tatsächlich lädt ihre Schwester Theodocie sie an Festtagen oft / zum Tanzen ein. Dort spielt sie auf der lieblichen Harfe, / und sobald sie singt, schweigen die weidenden Stiere voller Staunen: / [...] 
LEPIDINA.

$[\ldots]$

Parthenope tum culta manus miratur: ibi illa

Lacteolos et thyrsiculos et oluscula signat,

Inde latet forma nimiumque et dote superba. ${ }^{98}$ (IV, Vv. 99-101)

Die puellae der Vorstadt werden nicht als niedere Geschöpfe beschrieben, sondern ihre Tätigkeiten werden ausführlich dargestellt und mit ehrlicher Bewunderung und Wertschätzung bedacht. Die Beschreibung der puellae erfolgt ausserhalb des traditionellen bukolischen Genres und trägt zur Vielfalt der Darstellungs-, aber auch der ästhetischen und ethischen Wertepalette massgeblich bei.

Der fünfte Aufzug beginnt mit dem Auftritt Pianuris', der Personifikation von Pianura, einem Quartier der hügeligen Peripherie Neapels.99 Pianuris ist keine gewöhnliche schöne Nymphe, sondern ein Wesen bestehend aus Pflanze und Wasser; sie ist «dépossédée d'une forme humaine, loin d'une représentation mimétique avec le réel ». ${ }^{100}$ Während Macron über das nasse Wesen irritiert ist, spricht Lepidina Pianuris direkt an und bittet sie, ihr die vorbeiziehenden Figuren vorzustellen. Pianuris steigt unmittelbar ein, die geheimnisvollen Gestalten zu präsentieren und zu kommentieren, wobei sie das Ausserordentliche der Figuren vorwegnimmt (V, V. 19):

Planuris.

Descendunt, soror, et nemora et caua flumina currunt

Ad thalamos, mille antra deo uomere, et ab altis

Montibus indigenae Fauni proterunque ruuntque

Ad portas; iter ingentes non explicat Orcos,

Quos Acherusiacae fauces noua numina mittunt,

Stagnaque Baulorum, quos ostia pinguis Auerni

Emisere adytis lacus et fluitantis Araxi.

Mira illis sunt ora, soror, radiantia fronti

Lumina, sulfureis fumus de naribus efflat,

Tempora per serpunt rami mentoque rigescunt

98 LePidina. Die schöne Parthenope bewundert, was aus ihren Händen entstanden ist: Sie / zeichnet Stiele und kleine milchweisse Gemüse. / Danach versteckt sie sich, stolz auf ihre Vorzüge und ihre Schönheit.

99 Pianuris ist eine merkwürdige Erscheinung: Sie wird mit den Attributen der Rosen aus Paestum sowie der Veilchen vom Vesuv ausgestattet, wobei die Rosen wie schon bei Cicero und Vergil als Blumen der Venus gelten, während die Veilchen - gemeinsam mit den Lilien - für die Reinheit der Jungfrau stehen und hier neben der religiösen eine geographische Markierung mit sich führen. Siehe Casanova-Robin, Commentaire, S. 189.

100 Casanova-Robin, Commentaire, S. 188. 
Hircosae saetae; tum guttura collaque circum

Squalent sulfureae totoque in pectore crustae,

Cetera membra nigror merus occupat et situs et nox. ${ }^{101}$ (V, Vv. 12-24)

Nach dem Verweis auf die (mythologische) Herkunft der Figuren - die Berge und die Unterwelt - wird die Beschreibung von Gesicht, Brust und Körper mit « mira illis sunt ora » eingeleitet. Diese Bemerkung steuert den Blick des Lesers und nimmt die Wirkung der admiratio vorweg. ${ }^{102}$

Im Untertitel des fünften Aufzugs als Heroen angekündigt, erweisen sich die Gestalten als dunkle Figuren, die aus dem Rachen des Acheron, aus sumpfigen Gewässern des Arax, von den Bergen oder aus den Vulkanen steigen. Der Verweis auf den Arax kommt nicht von ungefähr, steht der armenische Fluss in der Literatur doch für das « univers fabuleux » des Orients. ${ }^{103} \mathrm{Er}$ ist charakterisiert «par ses ondoiements, signes de mystère et d'une esthétique de la courbe ».104 Der Anblick der Gestalten ist erstaunlich und sonderbar: Von ihrer Stirn werden Strahlen ausgeschleudert, aus ihren Nasen entströmt schwefeliger Rauch. Äste umwickeln ihre Stirn, das Kinn ist mit nach Ziege riechenden Borsten übersät, Hals und Brust sind vom Schwefel verkrustet, der Rest des Körpers mit schwarzem Schmutz überzogen.

Ils témoignent aussi d'un infléchissement de l'univers bucolique vers des territoires plus sombres, voire infernaux. ${ }^{105}$

101 Planuris. Sie kommen herab von den Wäldern, Schwester, und eilen an den Gewölben des Flusses / zum Brautgemach, unzählige Gottheiten brechen aus ihren Höhlen hervor, und von den hohen / Bergen treten und stürzen die eingeborenen Faune / zu den Türen; der Weg ist zu schmal für die ungeheuerlichen Riesen, / diese neuen Götter, dem Rachen des Acherons entsandt / und den Teichen von Bauli und den Mündungen des ergiebigen / Averno und den fliessenden Wogen des Arax. / Ihre Gesichter sind erstaunlich, Schwester, leuchtende Augen / auf der Stirn, Rauch entsteigt ihren schwefeligen Nasenlöchern, / Äste umschlingen ihre Schläfen, stinkende Borsten / sträuben sich am Kinn; dann sind die Kehle, der Hals / und die ganze Brust überzogen mit einer Schwefelkruste, / nichts als Schwärze bedeckt die übrigen Glieder und den Schmutz und die Nacht.

102 Casanova-Robin, Étude introductive, S. CCL. Casanova-Robin verweist auf weitere Werke der klassischen griechischen und lateinischen Literatur, die einer « esthétique de la surprise » folgen und beim Leser sowohl Freude und Vergnügen wie auch Staunen und Bewunderung zu erzeugen suchen. Als Beispiele nennt sie die Metamorphosen des Apuleius, Heliodoros' Aithiopika, Chariton von Aphrodisias mit Chaireas und Kallirrhoë.

103 Casanova-Robin, Commentaire, S. 189; vgl. Aen., VIII, V. 728. Weitere Verweise finden sich bei Propertius, Tibull, Lukan und Statius. Der Fluss wird stets als unheimlich und barbarisch beschrieben (ebd.).

104 Casanova-Robin, Commentaire, S. 189.

105 Casanova-Robin, Étude introductive, S. XLVIII. 
Ils participent d'une esthétique du composite qui préfigure celle d'un Arcimboldo quelques années plus tard et d'une mise en scène de l'identité campanienne, dans toutes ses particularités. ${ }^{106}$

Nicht nur der Anblick, auch die Teilnahme dieser Wesen im Hochzeitsaufzug zu Ehren der Götter Neapels ist unerwartet - würde man darin normalerweise keine dunklen, stinkenden Gestalten erwarten. Das vielseitige Porträt, das Pontano von Neapel entwirft, enthält nicht nur das Schöne und Angenehme, sondern auch das Primitive, Schmutzige und Beängstigende. Auffällig sind wiederum die olfaktorischen und visuellen Spektren, die in diesem Aufzug vom paradiesischen Garten bis hin zur vulkanischen Berg- und Unterwelt reichen. Die visuelle Dimension hingegen ist komplexer und mehrschichtiger. Die primäre Sicht ist auf den Aufzug gerichtet, auf die detaillierte Beschreibung der vorbeischreitenden Gestalten. Erst auf einer zweiten Ebene erwecken diese Figuren als Allegorien und Metaphern Bilder der neapolitanischen Landschaft und des Lebens auf dem Land, in der Stadt oder am Meer. Wie kreativ diese Bilder sein können, zeigt sich am Beispiel der Beschreibung des Oreaden Vesuv:

Planuris.

$[\ldots]$

Ventre quidem modico, at medio de pectore gibbum

Protendit, quanta est Bauiae cretatilis olla,

Qua miscet suibus pultes farcitque catinum;

Quodque pudet, nullas res hic habet et caret illis,

Pro quibus intumuit cucumis niger; inde Napeaeae

Hunc rident, rident et Oreades; ille superbum

Nutat et inflexo quassat nigra tempora cornu,

Quod longe horrescit saetis hinc inde reflexis.

At caluum caput, et nullo uestitur amictu;

Stant mento sentes horrentque ad pectora dumi.

Ah uereor, soror, et dicam tamen: huius ab ore

Curuantur geminae sannae, quarum altera pontum

Taetra petit fluctusque ferox et litora uerrit,

Altera Sarastris fauces, saxa horrida Sarni, ${ }^{107}$ (V, Vv. 246-259)

106 Casanova-Robin, Commentaire, S. 189.

107 Planuris. [...] Der Bauch ist ebenmässig, aber in der Mitte der Brust erstreckt sich / ein Höcker, gross wie ein kreidefarbener Kochtopf aus Bavia, / hier mischt sie [Porticia] den Mehlbrei für den Futtertrog der Schweine; / aber er schämt sich, dass ihm gewisse männliche Teile fehlen, / an deren Stelle bläht sich eine schwarze Gurke auf. Deshalb lachen / die Napeen und die Oreaden über ihn; er aber nickt / hochmütig und schüttelt seine schwarzen, mit einem gebogenen Horn geschmückten Schläfen, / lang, mit steifen 
Es wird zur Spielerei, diese originellen Bilder dem echten Vesuv zuzuordnen zum Beispiel den Höcker auf der Höhe seines Bauches oder die gekrümmten Hörner an seiner Stirn. Pontano erkundet die kreativen und sinnlichen Fähigkeiten der Sprache und weist damit eine normiert-konventionelle, ausschliesslich an der Antike ausgerichtete Literatur zurück.

Im sechsten Aufzug treten die eleganten Dryaden (Baumnymphen) und Oreaden (Bergnymphen) in Erscheinung. Nach einem Auftakt mit wechselseitigem Gesang der Dryaden und Oreaden erblickt Lepidina Patulcis - wiederum Personifikation eines neapolitanischen Quartiers, diesmal aber weder eine massige noch eine bäuerliche Erscheinung, sondern eine elegant tanzende Schönheit in einem noblen Gewand (VI, Vv. 13-14). ${ }^{108}$ Macron vergleicht Lepidina mit Patulcis: In diesem Moment ist Lepidina keine einfache Hirtin mehr, sondern wird, wie die Dryaden, zu einer eleganten Nymphe. Viel mehr als von Patulcis ist Macron jedoch von Antiniana gebannt, der nächsten der « heroines », die im Hochzeitsaufzug erscheint. Antiniana ist die Personifikation der Zweitresidenz Pontanos in Antignano bei Neapel. ${ }^{109}$ Sie tritt in verschiedenen literarischen Texten Pontanos auf, unter anderem in Lyra und im Eridanus, ${ }^{110}$ und vereint wiederum Mythologie und konkrete Lebenswelt:

\section{MACRON.}

Ecce uenit formosa, uenit decus heroinon, Et myrto diues serpellisque inclyta uirgo, Clara thymo longeque etiam clarissima melle Antiniana. Ruunt huius fama unidque amantes, Et bona pars sine dote petunt conubia nymphae. Ipa seni blandita, senem cupit, huius ab ore Et choreas agit et carmen meditata per hortos Laeta canit; stupet ad saepem mirata iuuentus.

Borsten, die auf beiden Seiten zurückfedern. / Aber sein Haupt ist kahl, und nichts ist von einem Gewand bedeckt. / Auf dem Kinn ragen Dornen empor und Dornengestrüpp auf der Brust. / Ah, ich fürchte mich, Schwester, aber ich werde es dir trotzdem sagen: Sein Mund / verzieht sich zu zwei Grimassen, eine der beiden grässlich, / erstreckt sich als wilde Woge bis zum Meer und durchfurcht die Küste, / die andere erreicht die Schlucht von Sarasti und die rauhen Felsen des Sarno, / [...]

108 Patulcis singt ein Klagelied: Ihr Geliebter Nivanus wird von Nisa auf deren Insel festgehalten. Auch Macron stellt sich als Teil der mythologisierten Welt heraus. Er kennt Nivanus, dieser selbst hat ihm davon berichtet, dass er von Nisa dazu verführt werde, auf der Insel zu bleiben. Macron verspricht Patulcis, zu Nivanus zu gehen und ihn zurückzuholen (Vv. 52-52).

109 Casanova-Robin, Commentaire, S. 197.

110 Ebd. 
Hinc sola incedit passuque elata superbo Inuitatque senem et suspiria ridet amantum.

Nec nosti, Lepidina, deam? ${ }^{111}$ (VI, Vv. 55-65)

Zuerst treten uns ihre pflanzlichen und duftenden Attribute entgegen: die Myrte - die Pflanze der Venus, mediterran und immergrün - und der (Feld-) Thymian - ein stark duftendes Heil- und Speisekraut. In der Kombination werden Thymian und Honig in der Bucolica Vergils als Attribute der schönen Liebenden genannt (vgl. Buc., VII, V. 37). ${ }^{112}$ In den Gärten tanzt und singt Antiniana, ${ }^{113}$ so dass die jungen Männer nur noch staunen können («stupet [...] iuuentus », VI, V. 62). Sie aber begehrt einen älteren Mann - einen senex, wie wir ihm auch im Actius begegnen und wie Pontanos Name in der Accademia lautet. Diese Beziehung zum senex holt die biographisch-poetologische Ebene spielerisch ein.

Auch Lepidina erinnert sich lebhaft an Antiniana, insbesondere an ihren Gesang, der von Orpheus' Verlangen nach Eurydike handelte. Erst mit Antinianas Gesang habe sie verstanden, was die Liebe und die Vereinigung in der Ehe bedeuten (VI, Vv. 69-71). Antiniana besitzt eine Flöte von Melidox, von demjenigen, „der den Gesang lehrt“. Ihr Gesang wird von sieben Nymphen begleitet und Urania - auch ein Werk Pontanos und an dieser Stelle Personifikation des ätiologischen Leitsterns - bereitet ihr die Szenerie:

Quin numeros meditata canit noua carmina uirgo.114 (VI, V. 78)

Im siebten Aufzug wird dieser neue Gesang der Antiniana abwechselnd mit einem Chor aus jungen Mädchen und Jungen wiedergegeben. Was als Zelebrieren der Hochzeit beginnt, geht über in eine Prophezeiung der Zukunft, in der die Geburt eines Stamms mit fachkundigen Landwirten (VII, Vv. 23-27),

111 Macron. Dort kommt die Schöne, es kommt der Glanz der Heldinnen: / Junge Frau, reich an Myrte und bekannt für ihren Feldthymian, / berüchtigt für ihren Thymian und seit langem am berühmtesten für ihren Honig, / Antiniana: Aufgrund ihres Ansehens eilen die Liebhaber von überall herbei, / und viele von ihnen halten ohne Gabe um die Hand der Nymphe an. / Sie selbst umschmeichelt einen alten Mann, einen alten Mann begehrt sie, und / tanzt einen Reigen im Garten und singt glücklich / ihre Melodien; am Zaun staunen die verwunderten jungen Leute. / Von hier geht sie allein, hochmütig und mit stolzem Schritt / und lädt den Alten ein und belächelt die Seufzer ihrer Liebhaber. / Kennst du sie nicht, Lepidina, diese Göttin?

112 Casanova-Robin, Commentaire, S. 197.

113 Zum Begriff «carmen meditata» siehe ebd. Als meditari wird das Komponieren von Liebesmelodien auf der Flöte zu Beginn von Vergils Bucolica bezeichnet (Buc., I, V. 1).

114 Und das junge Mädchen singt die Harmonien ihrer neu einstudierten Lieder. 
talentierten Handarbeiter(inne)n (VII, Vv. 29-32), kämpferischen Helden (VII, Vv. 34-38) und schliesslich eines Geschlechts von Hirten in der Nachfolge von Mopsus, Meliboeis - beides Hirten(sänger) der Bucolica Vergils - und von Pan, dem Faun und Begründer der bukolischen Dichtung, vorausgesagt wird. Ein Hirte (Vergil) wird in fremden Landen geboren werden, sich arm in der neapolitanischen Gegend ansiedeln und mit seinem Gesang die trockenen Felsen am Vesuv zum Erklingen bringen. Selbst die Bäume werden von seinem Gesang bewegt sein und ihn anflehen, nicht mit dem Singen aufzuhören.

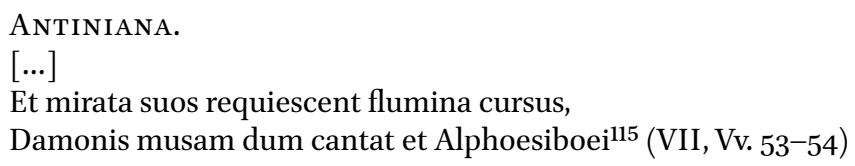

Das Motiv des rückwärtsfliessenden Flusses entnimmt Pontano Vergils Bucolica. Als Objekt der Bewunderung gilt nicht wie in der Bucolica der Gesang von Damon und Alphesiboeus, sondern jener von Vergil.

Pastorum Musam Damonis et Alphesiboei, immemor herbarum quos est mirata iuvenca certantis, quorum stupefactae carmine lynces et mutata suos requierunt flumina cursus, Damonis Musam dicemus Alphesiboei. ${ }^{116}$ (Buc., VIII, Vv. 1-5)

Die Wirkung des erstaunlichen Gesangs - ursprünglich von Orpheus ausgehend - wird von einem Dichter auf den nächsten übertragen, was Pontano an dieser wörtlich zitierten Stelle dokumentiert. ${ }^{117}$ Die Übertragung endet denn auch nicht mit Vergil, sondern geht in die Prophezeiung von Pontanos Geburt und die Ankündigung von ihm als zweitem Vergil über (VII, Vv. 57-61). Nach ihm werden weitere Sänger geboren werden und die Tradition

115 Antiniana. [...] Und es lassen die erstaunten Flüsse ihre Strömungen ruhen, / während er den Gesang von Damon und Alphesiboeus vorbringt.

116 Von der Muse der Hirten Damon und Alphesiboeus - während sie um die Wette sangen, staunte die Kuh und vergaß zu grasen, die Luchse waren von ihrem Lied gebannt, und die Flüsse veränderten ihren Lauf und standen still -, von der Muse des Damon und Alphesiboeus werden wir künden.

117 Der Verweis auf Orpheus und dessen magischen Gesang findet sich auch an folgenden Stellen: in Pontanos Urania, III, Vv. 1349-1350; in Vergils Buc., I, Vv. 38-39; III, Vv. 46, 69-71; VI, Vv. 27-31, 61, 64, 71, 84. Siehe CASANova-Robin, Étude introductive, S. CCLIV-CCLV. 
des bukolischen Gedichts weiterführen. Immer wieder werden neue Fäden an den Traditionsstrang der bukolischen Literatur hinzugewebt werden. ${ }^{118}$

Die poetischen Kriterien, die Actius im Dialog dargelegt hat, können wir in Lepidina auf vielfältige Weise erkennen. Am augenfälligsten ist sicherlich die mythologisierte und personifizierte Landschaft, die mit den Mitteln der Fiktion und der Übertragung neue und ausserordentliche Bilder schafft und ein lustvolles Spiel zwischen Realität und Fiktion erzeugt. Der Blick des Lesers wird oft mit einem Ausdruck des Staunens auf diese Personifikationen gelenkt, wobei das Spektrum der bestaunten Objekte sehr breit gefächert ist: von der klassischen Schönheit (Parthenope, Antiniana, Patulcis) über die massige Inselnereide (Capri) zu den monströsen Berggestalten, den primitiven Vorstadtmädchen und der körperlosen Pianuris. Im Dienst der admiratio steht die überaus sinnliche Sprache, die lebendige Bilder, Gerüche und Klänge heraufbeschwört. Mehrmals wird der Gesang als erstaunliche Fähigkeit der Figuren herausgestellt, was vor allem bei Parthenope und Antiniana von Bedeutung ist. Sie beide verkörpern Pontanos bevorzugte Gegenden (Neapel und Antignano), sind von erhabener Schönheit, beide sind Liebende und sie treten als Dichterinnen bzw. Sängerinnen auf. Nicht zuletzt darf Lepidina als Ganzes aufgrund des innovativen Umgangs mit dem Genre des bukolischen Gedichts als herausragendes Werk bezeichnet werden.

\subsubsection{De hortis Hesperidum}

$\mathrm{Ab}$ his superest reverti ad hortorum curam et suapte natura memorandam et quoniam antiquitas nihil prius mirata est, quam Hesperidum hortos ac regum Adonidis et Alcinoi itemque pensiles, sive illos Semiramis sive Assyriae rex Syrus fecit, de quorum opere alio volumine dicemus. ${ }^{119}$

118 Mit diesen Worten endet der Gesang Antinianas und die Perspektive wechselt zurück zu Lepidina und Macron. Die beiden beschreiben die Lippen der Antiniana als prall gefüllte Honigwaben. Macron berichtet davon, dass Antiniana hundert Bienenschwärme besitze - die Süssigkeit des Gesangs wird mit dem Bild der Imkerin zusammengeführt. Der Bezug zu den Bienen erinnert insbesondere an Petrarcas Bienengleichnis in den Familiares (I, 7), das auf Seneca zurückgeht: Genauso wie die Biene nur den wertvollsten Nektar aus verschiedenen Blüten holt und zusammenführt, sollen auch die Dichter nur das Beste aus ihren Quellen herausholen und für sich adaptieren. Das neu Geschaffene soll anders und besser sein als das, woraus es entstanden ist. Die Ekloge endet damit, dass Macron und Lepidina nochmals ihre Geschenke und ihre Worte an das Hochzeitspaar durchgehen und damit motivisch den Kreis zum Prolog schliessen.

119 C. Plinius Secundus der ÄLtere, Naturkunde, Lateinisch / Deutsch, Buch XIX: Botanik, Gartenpflanzen, herausgegeben und übersetzt von Roderich König et al., Zürich 1996, S. 39: «Nach diesen Ausführungen bleibt noch übrig, vom Gartenbau zu reden, der sowohl für sich allein erwähnenswert ist als auch weil das Altertum nichts früher bewunderte als die Gärten der Hesperiden, der Könige Adonis und Alkinoos, ebenso die 
Die Begründung von Plinius dem Älteren, es lohne sich, über den Gartenbau zu sprechen, weil die Gärten an sich erwähnenswert und das Erste gewesen seien, das die Antike bestaunt und bewundert habe («nihil prius mirata est ») -, können wir mit gutem Gewissen auch für Pontano anführen. Es sind insbesondere der hohe kulturelle Stellenwert und der symbolische Gehalt, die Pontano zu einem passionierten Gärtner sowie zu einem Bewunderer der Gärten Kampaniens und Italiens machen. Nicht zuletzt sind es die antiken Texte über Garten und Landbau, denen er besondere Aufmerksamkeit schenkt. ${ }^{120}$

De hortis Hesperidum ist dem Anbau, der Pflege und der Verwendung des Zitrusbaums gewidmet. ${ }^{121}$ Das Lehrgedicht entstand um $1500^{122}$ und

hängenden Gärten, seien sie nun von Semiramis oder Syros, dem König von Assyrien, angelegt worden, über deren Aufbau wir in einem anderen Buch reden wollen. »

120 Hélène Casanova-Robin, Des métamorphoses végétales dans les poèmes de Pontano: mirabilia et lieux de mémoire, in:VIRGINIE LE ROUX (Hg.), La mythologie classique dans la littérature néo-latin, en hommage à Geneviève et Guy Demerson, Clermont-Ferrand 2011, S. 26o.

121 Pontano unterscheidet den citrius vom citrus, von beiden Arten ist in De hortis Hesperidum die Rede. Der citrius entspricht der Amalfizitrone (cedro di Amalfi - deshalb auch die italienische Übersetzung cedro) sowie der lateinischen Bezeichnung citrus medica. Der citrus hingegen kann sowohl der "gewöhnliche“ Zitronenbaum, als auch Thuja (u. a bei Plinius) sein. Ich werde in der Folge die generischen Begriffe „Zitrusbaum“ und „Zitrusfrucht" verwenden, weil es Pontano - so glaube ich - weniger um eine spezielle Art des Zitrusbaums und mehr um die Zitrusfrucht in ihren verschiedenen Ausprägungen als typische Pflanze Kampaniens geht.

Der Zitrusbaum war kein (nennenswertes) Element der griechischen oder lateinischen Mythologie. Die Zitrone (citrus medica) war in Griechenland seit Alexander dem Grossen verbreitet und wurde aufgrund ihres medizinischen Werts zum «Symbol der Abwehr allen Zaubers, alles Bösen». Sie galt als kräfteweckend, appetitanregend und lebenserhaltend und war das Attribut von Sterbenden und Verstorbenen - bei Beerdigungen trugen Sargträger oder Angehörige eine Zitrone in der Hand. Ebenfalls war die Zitrone in allen christlichen Ritualen, die eine Erneuerung oder Wandlung herbeiführen sollten, vertreten. Sie entwickelte sich zum Symbol für «Trauer», «neues Leben », « Hochzeit», « treue Liebe», «Schutz vor Zauber», « Reichtum » und « Fruchtbarkeit» und wurde mit dem Apfel der Hesperiden identifiziert. Nach Kampanien kam die Zitrone sehr wahrscheinlich durch die jüdische Bevölkerung, in deren Kultur die Zitrone eine zentrale Rolle spielte. Neapel wurde Ausgangspunkt für Zitronenlieferungen an jüdische Völker in ganz Europa. Die jüdische Symbolik, in der die Zitrone die «Sünde des Herzens » verkörpert, scheint für Pontano kaum von Bedeutung gewesen zu sein. Siehe MARIANne BEuCHERT, Symbolik der Pflanzen, Lemma « Zitrone », Frankfurt a. M. 2004, S. 353-354. Zur Symbolik der Zitrone im jüdischen Brauchtum siehe ebenfalls PiErre Laszlo, Storia degliagrumi. Usi, culture e valori dei frutti più amati del mondo, traduzione di Salvatore Proietti, Roma 2004, S. 24.

122 Für eine ausführliche Entstehungs- und Editionsgeschichte siehe AntoniEtTa IAcono, Il De hortis Hesperidum di Giovanni Pontano tra innovazioni umanistiche e tradizione classica, in: Spolia 1 (2015), S. 2-3. Iacono vermutet, dass Pontano schon früher mit 
umfasst zwei Bücher, das erste mit 6o7, das zweite mit 581 Hexametern. In beiden Büchern fügen sich mythologische und botanische Erläuterungen ineinander. ${ }^{123}$

Als grundlegende Quellen gelten Plinius' Naturalis Historia und Vergils Georgica, ${ }^{124}$ wobei Pontano nicht den Landbau im Allgemeinen, sondern nur den Anbau der Zitrusbäume beschreibt. Genauso wie die Werke seiner Vorgänger vielschichtige Texte sind, würde es für De hortis Hesperidum zu kurz greifen, es lediglich als Lehrgedicht zu verstehen. Die enkomiastische Prägung, die mythologische Ätiologie, die enorme Dichte an intertextuellen Verweisen sowie die metapoetische Dimension machen das Gedicht zu einem überaus vielfältigen Textgebilde. ${ }^{125}$

Die horti Hesperidum sind Gianfrancesco II. Gonzaga, Fürst von Mantua, gewidmet, zugleich sind die Orangenbäume Symbol der Herrschaft der Aragonesen und deren Reich. ${ }^{126}$ Von Gonzaga erhofft sich Pontano Hilfe für Neapel, nachdem die aragonische Königsfamilie von den französischen Königen Karl VIII. und Ludwig XII. zur Abdankung gezwungen worden war. Das Reich des Herzogs dient auf vielfältige Weise als Analogie zu Neapel und Pontano: Die Uferhänge des Gardasees sind genauso wie in Kampanien für den Anbau von Zitrusbäumen bekannt. In Mantua wurde Vergil geboren, als dessen neapolitanisches Pendant sich Pontano schon in Lepidina inszenierte.

Der Baum mit den goldenen Früchten ist - so singen es die Parzen am Ende des ersten Buches - dafür bestimmt, die Königs- und Herrenhäuser zu

der Niederschrift begonnen habe, weil einzelne Motive schon in frühen Schriften auftauchen - so in Urania (I, 483), mit deren Verfassung Pontano 1475 begann und wo der Tod des Adonis bereits mit dem Zitrusbaum in Verbindung gebracht wird. Ihre Argumente sind schlüssig, aber nicht zwingend.

123 Dass Wissenschaft und Mythologie sich gegenseitig ergänzen, kann schon in der früheren Dichtung Urania, die der Astronomie und der Astrologie gewidmet ist, beobachtet werden. Siehe dazu folgende Seite von Iacono: http://www.federica.unina.it/lettere-efilosofia/latinistica5-llmu/produzione-poetica-giovanni-pontano/ (Stand April 2021).

124 In Vergils Georgica findet sich ein Vers, in der Vergil die Dichtung über Obstbäume den anderen Dichtern überlässt. Vgl. Georg., IV, Vv. 144-148. Siehe Carlo Caruso, Adonis. The Myth of the Dying God in the Italian Renaissance, London/New York 2013, S. 13. Ebenso GUSTARELLI, Introduzione, S. 20.

125 IACono, Il De hortis Hesperidum, S. 1.

126 Ebd., S. 6. Die Orange rückt auch para-etymologisch («arangio/aragonesi ») in Verbindung zum Königshaus. Es ist sogar überliefert, dass bei der Hochzeit von Eleonora d'Aragona und Ercole d'Este im Jahr 1473 mit Goldfolie überzogene Orangen serviert wurden. Die Verbindung zu den mala aurea der Hesperiden liegt überaus nahe, zum einen wegen des goldenen Überzugs, zum anderen in der Anspielung an Herkules, dessen Name der Bräutigam trägt und der die Äpfel der Hesperiden gestohlen hat. 
schmücken und den « sacris [...] vatibus » als Stoff zu dienen $\left(\mathrm{I}, \mathrm{Vv} \cdot 55^{\circ}-553\right) \cdot{ }^{127}$ Der Zitrusbaum kann damit auch als Symbol der Dichtung verstanden werden; die Ausführungen zu seinem Ursprung, zu Anbau und Pflege sowie seiner starken Wirkung auf die Sinne können als Poetik gelesen werden - genauso wie auch Vergils Georgica poetologisch gedeutet wird. Trifft die Analogie zwischen Zitronenanbau und Poetik zu, müsste der Zitrusbaum - entsprechend der admiratio-Poetik Pontanos - mit dem Staunen zusammenhängen.

Pontano umrahmt den Lehrteil über den Anbau der Zitrusbäume mit Einschüben, in denen adaptierte Versionen zweier Mythen erzählt werden: des Raubes der Äpfel der Hesperiden (I, Vv. 102-104, 168-188) sowie der Metamorphose des Adonis (I, Vv. 68-101).

Il poema ha il suo fulcro nel mito delle Esperidi, le ninfe che custodivano i pomi dorati, i cedri, in un giardino incantato presso il monte Atlante, su questo mito il Pontano innesta, però, un'importante novità, immaginando questi frutti nati dal corpo di Adone, il giovane amato da Venere, e importati in Italia da Ercole, che li avrebbe lasciati in dono in Campania alla ninfa Ormiale. ${ }^{128}$

Die mythologische Einführung und Einbettung dient zum einen der Ätiologie, zum anderen der attraktiven fiktiven Anreicherung des "trockenen“ botanischen Lehrstoffes. ${ }^{129}$ Die Mythen werden in neu erfundenen Varianten erzählt. Insbesondere werden sie in die Region Kampaniens und die Lebensund Literaturwelt Pontanos eingebettet. ${ }^{130}$

Der Legende nach träumte Vergils Mutter in der Nacht vor seiner Geburt, sie gebäre einen Lorbeerzweig, der sich - als er den Boden berührte - auf wundersame Weise in eine üppige, blühende Pflanze voller Früchte verwandelte. ${ }^{131}$ Der Lorbeer ist die heilige Pflanze Apollons, gleichzeitig ist der Lorbeer die Pflanze der Dichter und stellt die Ehrung ihrer Kunst dar. Vergil und Pontano vergleichen den Lorbeer mit dem Zitrusbaum:

127 Im 16. Jahrhundert, als Orangerien in ganz Europa in Mode kamen, wurden die Zitrusfrüchte auch zum Symbol von Reichtum und Macht. Die Beschaffung der Zitrusbäume war sehr teuer, die Pflege überaus aufwendig. Siehe Beuchert, Symbolik der Pflanzen, Lemma «Zitrone», S. 354.

128 Siehe das Lemma « De hortis Hesperidum » auf der bereits genannten Seite http://www. federica.unina.it/lettere-e-filosofia/latinistica5-llmu/produzione-poetica-giovannipontano/ (Stand April 2021).

129 IACONO, Il De hortis Hesperidum, S. 8.

130 Ebd., S. 8.

131 Caruso, Adonis, S. 17. Die Legende geht zurück auf die Vita vergilii von Donatus. 
Media $^{132}$ fert tristis sucos tardumque saporem

felicis mali, quo non praesentius ullum, pocula si quando saevae infecere novercae miscueruntque herbas et non innoxia verba, auxilium venit ac membris agit atra venena. ipsa ingens arbos faciemque simillima lauro; et si non alium late iactaret odorem, laurus erat: folia haud ullis labentia ventis; flos ad prima tenax; animas et olentia Medi ora fovent illo et senibus medicantur anhelis. ${ }^{133}$ (Georg., II, Vv. 126-135)

Ipsa quidem lauro foliisque et cortice et ipso Stipite tum similis, tum frondescente iuventa, At cono inferior ramisque valentibus impar, Nam florum longe candore et odoribus anteit. ${ }^{134}$ (I, Vv. 59-62)

Während Vergil die beiden Bäume neutral gegenüberstellt und auf die Heilkräfte der mala Medicae fokussiert ist, stellt Pontano den Zitrusbaum aufgrund seiner visuellen (weisse Farbe der Blüten) und olfaktorischen Vorzüge über den Lorbeer. In Analogie zum Lorbeerbaum wird Pontano den Zitrusbaum mit einer Metamorphose - derjenigen des Adonis - unterlegen und ihn als Pflanze seiner Dichtung definieren (I, V. 553). Die aemulatio zwischen Lorbeer und Zitrusbaum steht in einem übertragenen Sinne für die aemulatio

132 Pontano identifiziert die mala Medicae Vergils mit dem citrius (I, V. 53). Dieser Vergleich findet sich auch in anderen Quellen - ob Vergil tatsächlich den Zitrusbaum im Kopf hatte, ist jedoch umstritten. Bezeichnend ist, dass in einigen Quellen die mala Medicae als Synonyme für die mala hesperidum und die mala aurea genannt werden. Siehe beispielsweise bei Otто BRUnfels, Onomastikon medicinae, Lemma «mala Hesperidum », Strasbourg 1534. Ein digitalisiertes Exemplar der Erstausgabe von 1534 aus dem Bestand der Bibliothèque du Palais des Arts de Lyon findet sich auf Google Books (Stand April 2021).

133 Medien bringt den sauren Saft und langen Nachgeschmack seiner gesegneten Zitrone, und wenn einmal böse Stiefmütter einen Gifttrank gebraut und Kräuter und Unheilsworte beigemischt haben, kommt kein Gegenmittel wirksamer zu Hilfe und treibt das schwarze Gift aus den Gliedern. Der Baum selbst ragt hoch, ist dem Lorbeer sehr ähnlich, und verströmte er nicht weithin anderen Duft, wäre er der Lorbeer. Nie fallen seine Blätter vom Wind; die Blüte haftet ausnehmend fest; die Meder lindern damit übelriechenden Atem und Mundgeruch und heilen Atemnot bei Greisen.

134 Alle Zitate aus De hortis Hesperidum stammen aus Pontano, Dai „Carmina“, S. 325-391. Die Übersetzungen ins Deutsche stammen von der Autorin (A.E.) in Anlehnung an die Übersetzung ins Italienische von Andrea Gustarelli: « Er ist dem Lorbeer ähnlich, nicht nur von den Blättern, der Rinde / und dem Stamm her, sondern auch in seinem jugendlichen Laubwerk, / doch sein Rumpf ist tiefer und die Äste weniger kräftig, / während er ihn in der weissen Farbe und im Duft der Blüten bei weitem übertrifft. » 
zwischen Vergil und Pontano - wobei Pontano sich kühn als deren Gewinner inszeniert. ${ }^{135}$

Vergil bringt die mala Medicae nicht explizit mit den mala Hesperidae in Verbindung, wie Pontano dies tut. Pontano ist, in den Worten Iaconos,

principale promotore di questa identificazione in funzione di un'area geografica, quella propriamente campana, al quale il mito del giardino delle Esperidi e della ricchezza dei suoi frutti si confaceva proprio alla proverbiale ferocità di quel territorio. ${ }^{136}$

So beginnt die Dichtung nach der Widmung an den mantuanischen Fürsten mit der Nennung der hesperischen Gärten als Ursprung des Zitrusbaums. Der Wunderbaum der Hesperiden gilt mit seinen goldenen Früchten als «Symbol ewiger Jugend oder der Liebe und der Fruchtbarkeit »; Zeus und Hera hatten ihn als Hochzeitsgeschenk von Ge erhalten. ${ }^{137}$ In der Version von Apollonios Rhodios (IV, Vv. 1398 ff.) sind die Bäume durch eine von Orpheus beschworene

135 Implizit werden weitere Parallelen wachgerufen: Der Lorbeer ist das Attribut Apollons, mit Lorbeer reinigte er sich vom Blut des Pythondrachens, in einen Lorbeerbaum verwandelte sich Daphne, die sich seiner Liebe widersetzte. Dem Lorbeer werden « entsühnende[...], kathartische[...] Kräfte» zugeschrieben, er ist das Symbol für Sieg und Triumph, ebenfalls haben die Priester(innen) des delphischen Orakels Lorbeer gekaut, um ihre seherischen Kräfte zu entfalten. Gleichzeitig ist er natürlich das Attribut der Dichter und Sänger und steht für Inspiration und die Kraft, « zu bezaubern und zu entrücken », genauso wie für immerwährenden Ruhm. Als « Ewigkeits- und Unsterblichkeitssymbol » findet er «seit der Renaissance in Mitteleuropa im Begräbniskult Verwendung ». Siehe Beuch ert, Symbolik der Pflanzen, Lemma « Lorbeer », S. 193-195.

${ }_{13} 6$ Iacono, Il De hortis Hesperidum, S. 9-10, Fn. 49. Iacono spricht auch von einer « innovativa equiparazione » von «agrumi » und «pomi », die Pontano dazu nutze, den Mythos an Kampanien anzubinden (ebd.). Seit wann die Äpfel der Hesperiden mit Zitrusfrüchten identifiziert werden, ist schwierig zu sagen und wird in verschiedenen Quellen unterschiedlich datiert und zugeordnet. Helena Attlee etwa spricht in ihrem überaus lesenswerten Buch The Land Where Lemons Grow. The Story of Italy and Its Citrus Fruit (London 2014) davon, dass diese Identifikation bereits im 2. Jahrhundert vor Christus gängig gewesen sei (S. 11). Im 16. Jahrhundert gestaltete Nicolò dei Pericoli (Il Tribolo) für Cosimo de' Medici den Garten der Villa Medici von Castello als Garten der Hesperiden mit unzähligen Arten und Varianten von Zitrusbäumen (ebd.). In humanistischen Quellen findet sich vor allem die Anbindung der Zitrusfrüchte an Kampanien. Iacono nennt beispielsweise Coluccio Salutati (Conquestio Phillidis) und Petrarca (Itinerarium ad sepulcrum Domini nostri Ihesu Christi); beide stellen einen Zusammenhang der Zitrusfrüchte mit Kampanien, insbesondere mit Gaeta und Formia, her.

Der kleine Pauly, Lemma « Hesperiden », Bd. 2, S. 1118. 
Metamorphose aus «Staub und Erde » entstanden: ${ }^{138}$ « $[. .$.$] la métamorphose$ informe la mémoire sous l'effet de l'incantation poétique. »139

Plus qu'un ornatus, la fable de métamorphose est le lieu même de la création, «le secret du miracle poétique »[... $]^{140}$

Der Zitrusbaum, den Pontano als Wunderbaum der Hesperiden identifiziert, birgt in sich das Zeugnis der transformativen Wirkkraft von Orpheus Gesang, wird zum Sinnbild der Hochzeit und zum Symbol für die Heldentaten des Herkules.

Abgeschlossen wird der erste Abschnitt über die Herkunft des Baums mit der Zuschreibung an Venus, deren Trauer um Adonis er ewiglich symbolisiert. Die Motive der Erinnerung und der Trauer sind bewusst gewählt und ins Zentrum gestellt, bildet doch der Trauergesang über die verstorbene Geliebte eines der Leitmotive von Pontanos literarischem Werk.

Orbe etenim hesperio niasique ad litora quondam

Oceani auriferis primum sese extulit hortis

Citrius, arboreæ referens præconia palmæ.

$[\ldots]$

Quin gravida e ramis, triplici distincta colore,

Mala nitent virides primum referentia frondes;

Hinc rutilant fulvoque micant matura metallo,

Flore novo semper, semper quoque fotibus aucta,

Perpetuum Veneris monumentum at triste dolorum. ${ }^{141}$ (I, Vv. 53-67)

Die Ausfaltung der mythologischen Ursprünge zu Beginn des Lehrgedichts wird im Dialog Aegidius von Pontanos Freund Hieronymus Carbo gelobt - im Gegensatz zu Vergils Text über die Natur der Bienen, der in die Beschreibung der Bienen einsteigt, ohne von deren (mythischen) Anfängen zu berichten:

[...] videam Iovianium, qui conciliationi huic nostrae praesidet, locutorum de citirorum natura, ut de arbore peregrina, ut de cultu eius a nemine tradito, coepisse a loco unde in Italiam advecta fuerat ac de arboris ipsius primordiis

138 Ebd.

139 Casanova-Robin, Des métamorphoses végétales, S. 261.

140 Ebd., S. 263.

141 Einst erhob sich im hesperischen Gebiet am Strand / des niasischen Ozeans, im goldenen Garten, der erste / Zitronenbaum, an die Vorzüge der Palme erinnernd. / [...] / Volle Früchte hängen an den Ästen, in drei verschiedenen Farben: / Zuerst glänzen die Früchte im gleichen Grün der Blätter, / dann färben sie sich rötlich und, wenn sie reif sind, funkeln sie wie Gold, / immer werden neue Blüten und Früchte hervorgebracht, / ewiges und trauriges Denkmal von Venus' Schmerz. 
quanquam fabulose, poetico tamen more tradidisse, ne ante de cultu eius praeciperet quam quae et qualis esset arbor ostendisset. ${ }^{142}$

Im Actius nennt Pontano dieses Vorgehen - « den Gesang mit Erfindungen und Fabeln » auszufüllen - als Mittel, dem Gesang Erhabenheit zuzuführen und ihn « zur Bewunderung anwachsen » zu lassen. ${ }^{143}$

Die Metamorphose des Adonis in einen Zitrusbaum wird als Adaption des ovidischen Adonis-Mythos erzählt.

Ambrosio mox rore comam diffundit et unda

Idalia corpus lavit incompertaque verba

Murmurat ore super supremaque et oscula iungit.

Ambrosium sensit rorem coma, sensit et undam

Idaliam corpus divinaque verba loquentis;

Hæserunt terræ crines riguitque capillus

Potenta in radice et recto in stipite corpus,

Lanugo in teneras abiit mollissima frondes,

In florem candor, in ramos brachia et ille,

Ille decor tota diffusus in arbore risit;

Vulnificos spinæ referunt in cortice dentes,

Crescit et in patulas aphrodisia citrius umbras. ${ }^{144}$ (I, Vv. $\left.77-88\right)$

[...] „luctus monimenta manebunt

semper, Adoni, mei, repetitaque mortis imago

annua plangoris peraget simulamina nostri.

at cruor in florem mutabitur. an tibi quondam

femineos artus in olentes vertere mentas,

142 Pontano, Dialoge, S. 554-555: «[...] zumal ich sehe, dass Jovianus, der unserer Versammlung vorsteht, als er über die Natur der Citrusbäume sprechen wollte wie über einen fremden Baum, dessen Pflegemethode von niemand überliefert wurde, bei dem Ort begann, von wo aus er nach Italien gebracht wurde, und die ersten, wenn auch fabelhaften Anfänge des Baumes dennoch nach dichterischer Sitte überlieferte, um nicht zuerst über die Pflege des Baumes zu belehren und danach erst zu zeigen, was für ein Baum und wie er beschaffen sei. »

143 Pontano, Dialoge, S. 506-507.

144 Bald darauf breiten sich die Haare aus ambrosischen Tropfen aus und idalisches / Wasser wäscht seinen Körper, sie murmelt unverständliche Worte auf seine / Lippen und vereinigt sich in letzten Küssen mit ihm. / Die Kopfhaut spürte den ambrosischen Tau, der Körper nahm die idalischen / Wasser und die von ihr gesprochenen göttlichen Worte wahr; / die Haare erreichten den Boden und erstarrten / zu mächtigen Wurzeln, der Körper richtete sich zu einem Stamm auf, / sein weicher Bartflaum verschwand in jugendlichen Blättern, / in Blüten verwandelte sich das schimmernde Weiss, in Äste seine Arme, / seine Schönheit erstrahlte verteilt im ganzen Baum; / die Dornen in der Rinde erinnern an die Zähne, die ihn verletzt haben, / und es wächst der aphrodisische Zitrusbaum in ausgedehnten Schatten. 
Persephone, licuit: nobis Cinyreïus heros invidiae mutatus erit?" - sic fata cruorem nectare odorato sparsit; qui tacuts ab illo intumuit sic, ut fulvo perlucida caeno surgere bulla solet. nec plena longior hora facta mora est, cum flos de sanguine concolor ortus, qualem, quae lento celant sub cortice granum, punica ferre solent. brevis est tamen usus in illo: namque male haerentem et nimia levitate caducum excutiunt idem, qui praestant nomina, venti. ${ }^{145}$ (Ovid, Met., X, Vv. 725-739)

Bei Ovid wird die Metamorphose dadurch eingeleitet, dass Venus das Blut des Adonis mit «duftendem Nektar» besprengt. In De Hortis Hesperidum wird die Verwandlung ritualisiert und erweitert. Der rituelle Charakter der Sprache wird durch die repetitio in den Versen 77-81 untermalt. Insbesondere wird das (Zauber-)Ritual um die «incomperta [...] verba » (I, V. 78), die als «divina[] verba» (I, V. 81) wahrgenommen werden, ergänzt. Die magisch anmutende Sprache wird zu einem wichtigen Bestandteil der Verwandlung - sie erinnert daran, wie Orpheus mit seinem Gesang die Natur und insbesondere die Bäume der hesperischen Gärten aus der Verwandlung hat entstehen lassen. Während sich bei Ovid Adonis' Blut innerhalb kurzer Zeit in Anemonen verwandelt, verwandelt sich der Körper des Adonis in De Hortis Hesperidum nach und nach in Wurzel, Stamm, Äste, Blätter und Blüten des Zitrusbaums. Augenfällig ist damit insbesondere der Ausbau der Bildlichkeit; die Transformation des Körpers in eine Pflanze ist anschaulich beschrieben und rhythmisch untermalt. ${ }^{146}$

145 Ovid, Metamorphosen, Lateinisch / Deutsch, herausgegeben und übersetzt von Gerhard Fink, Düsseldorf / Zürich 2004, S. 524-527: « [...] „Trotzdem soll euch nicht alles verfallen, und die Erinnerung an mein Leid soll ewig bleiben. Eine heilige Handlung, Adonis, wird Jahr für Jahr deinen Tod wiederholen, und ein Nachhall meiner Klage sein. Dein Blut aber soll zu einer Blume werden - oder durftest nur du einst einen Frauenleib in wohlriechende Minze verwandeln, Persephone, während man mir des Adonis Verwandlung verargt?" So sprach sie und sprengte duftenden Nektar über das Blut. Kaum war es damit in Berührung gekommen, da quoll es auf, gleich wie oftmals aus bräunlichem Morast schillernde Blasen aufsteigen. Noch war keine ganze Stunde vergangen, da war aus dem Blut eine blutrote Blume gewachsen, ähnlich der Blüte des Granatapfelbaums, der seine Kerne unter zäher Schale verbirgt. Allerdings kann man sich an der Blüte nur kurze Zeit freuen; sie hält sich nur schlecht und ist allzu zart und vergänglich, und so verweht sie der Wind, der ihr auch den Namen gab: Anemone. »

146 Casanova-Robin hat festgestellt, dass die Körperteile als Spondäen, die Pflanzenteile als Daktylen dargestellt sind. Siehe CASAnova-Roвın, Des métamorphoses végétales, S. 253. 
Die Anemone ist flüchtig und verweht im Wind, der Zitrusbaum hingegen ist ein robuster, immergrüner Baum (I, Vv. 9o-93). ${ }^{147}$ Als monumentum (I, V. 67) der Erinnerung ist der Zitrusbaum sehr viel beständiger als die Anemone, ${ }^{148}$ als Ikone und insbesondere als poetologisches Symbol ist er vielschichtiger und komplexer.

Dass der Baum sowohl im Winter als auch im Sommer blüht und Früchte trägt, wird als staunenswerte Eigenschaft beschrieben:

Ergo et frondentem bruma mirabere et æstu Florentem, auratis utroque et tempore malis Fulgentem: [... $]^{149}$ (I, Vv. 439-441)

Wie in Lepidina zeigt die Voraussage „Du wirst darüber staunen“ nicht nur die Ausserordentlichkeit des Zitrusbaums, sondern ist als Hinweis an den Leser zu verstehen: Was berichtet wird, darüber wird oder soll der Leser staunen.

Nicht nur Venus, sondern auch der poetische Gesang über ihre Sehnsucht nach Adonis vermögen eine Verwandlung heraufzubeschwören. So hat Catull an den Ufern des Gardasees mit ebendiesem Gesang Weiden in Zitrusbäume mit hesperischen Früchten verwandelt.

Munus et hoc, Cytherea, tuum, dum forte canentem

Ad virides Saloi salices tua dulcia furta,

Et pueri amplexus teneros et Adonidis ignes

Miraris vatem egregium, cui candida plaudit

Verona et liquidis Athesis favet assonus undis.

Ille suas canit ad volucres, sua reddit Adonim

Silva, dionææ ludunt ad carmina nympæ;

Ipsa tuos repetis lusus, repetis hymenæos,

Per silvas, per saxa sonat tibi gratus Adonis,

Antra per et valles resonat formosus Adonis:

«Huc, o Adoni, ades, huc ades, oh mihi dulcis Adoni. »

Addis et his etiam suspiria: suspirarunt

Et tecum salices et tecum flumina; dumque

Et flectunt salices ramos et flumina cursum,

Illicet et salices frondes et poma tulerunt

Hesperidum nemoris (nam sic, dea grata, tulisti),

Illicet et fluvii gaudent cyrenide silva

Detiluisse novoque coma nituisse decore,

147 Vergil hat in den bereits zitierten Versen die Blätter des medischen Baums als stark und widerständig beschrieben, vgl. Georg., II, Vv. 133-134. Pontano nimmt diese Aussage auf.

148 Beuche RT, Symbolik der Pflanzen, Lemmata «Anemone», «Zitrone», S. 15, 353.

149 Du wirst staunen über die grünen Blätter im Winter und das Blühen der Blüten / im Sommer und das Glänzen der goldenen Früchte in / beiden Jahreszeiten [...] 
Gaudet et ipsa suo Verona ornata Catullo,

Altisonsique favet reflexa e montibus echo,

Sirmiaque auratis resplendent rura volemis. ${ }^{150}$ (I, Vv. 211-231)

Gekonnt fliessen in dem Abschnitt die Stimmen der Venus und Catulls ineinander, der Gesang mündet in der Metamorphose der Bäume. Pontano illustriert an dieser Stelle den Ursprung, die Qualität und die Auswirkung staunenswerten Gesangs: Der Ursprung ist die göttliche Inspiration - an dieser Stelle ist es Venus, die um Adonis trauert -, die Qualitäten sind der mythologische Gehalt sowie der sehnsuchtsvolle Trauergesang, die Auswirkung ist zum einen die sich verwandelnde Natur, zum anderen die Ehre, die Catull als Dichter zuteil wird - symbolisiert durch einen Zitrusbaum. Wird zuvor der Leser als Du angesprochen, ist es hier Venus, an die sich der Erzähler wendet. Venus wird in das Jetzt geholt, genauso wie der Gesang Catulls mit präsentischer Wirkung wiedergegeben wird.

Als Teil des Adonis-Mythos wird der Zitrusbaum zum Baum der Venus ${ }^{151}$ sowie zum Symbol der Trauer um die verlorene Liebe - Letzteres wird von Casanova-Robin als «thème obsessionnel et véritable ferment de la création pontanienne » bezeichnet. ${ }^{152}$ Tatsächlich begegnet die Verbindung von Zitrusbaum und Trauergesang im Werk Pontanos immer wieder, zum Beispiel in der Ekloge Meliseus. Dort wird beschrieben, wie Meliseus - Alter Ego des

150 Auch das ist dein Geschenk, Kythereia, und vielleicht hörst du bewundernd den ausgezeichneten Dichter, / der in den grünen Weiden von Salò deine süssen Liebesfluchten besingt / und die zärtlichen Umarmungen und die Leidenschaft des Adonis, / und es klatscht die glänzende Verona und die Etsch stimmt mit ihren heiteren Wellen schwärmend mit ein. / Er singt seinen Vögeln zu, ruft Adonis an in seinem Wald / und die dionysischen Nymphen tanzen zu seinem Gesang; / du selbst erneuerst die Spiele, wiederholst die Hochzeitsfeier, / in den Wäldern und an den Felsen erklingt der Name deines anmutigen Adonis, / in den Höhlen und in den Tälern erklingt der schöne Adonis: / « Komm hierher, Adonis, komm hierher, oh mein lieblicher Adonis. » / Fügst du mit einem Seufzer hinzu, und mit dir seufzen / die Weiden und es seufzen die Flüsse; und während / sich die Äste der Weiden und der Lauf der Flüsse krümmen, / bringen die Weiden unmittelbar Blätter und Früchte / der hesperischen Gärten hervor (die du, liebliche Göttin, hergebracht hast), / und sofort freuen sich die Flüsse, in diesen Zitronenwald zu fliessen / und die Häupter der neuen Bäume zum Strahlen zu bringen, / und die geschmückte Verona freut sich über ihren Catull, / und es applaudiert das Echo der klingenden Berge, / und die Felder von Sirmione glänzen voller grosser goldener Zitrusfrüchte.

151 In der Elegie Ariadnam uxorem mortuam alloquitur der Liedersammlung Eridanus wird der Ort unter den Zitrusbäumen als Liebesnest beschrieben. Siehe IAcono, Il De hortis Hesperidum, S. 6, Fn. 36.

$15^{2}$ Casanova-Robin, Des métamorphoses végétales, S. 260. 
Dichters - unter Zitrusbäumen den Tod seiner Frau beklagt. ${ }^{153}$ Die Zypressen und Zitrusbäume stimmen in seinen Gesang mit ein.

Auch in De hortis Hesperidum trauert der Erzähler um den Tod seiner Frau. Er erinnert sich daran, wie er gemeinsam mit ihr Zitrusfrüchte geerntet hat und sie - inspiriert von der Frucht der Venus - gemeinsame Liebesstunden verbrachten. Wie Pontanos Frau würde auch die Frau des Lesers die prächtigen Zitrusfrüchte bestaunen: «Et mirata sinum pomis gravioribus implet. »154 (I, V. 317) Der Zitrusbaum dient als Erinnerung an die Geliebte, ${ }^{155}$ als Symbol von Liebe und Sexualität, seine Früchte werden bestaunt.

Nach der Entstehung des „mythologischen“ Zitrusbaums wird von dessen Transport von Griechenland nach Italien erzählt. Die Äpfel des hesperischen Wunderbaums sind im Zuge von Herkules' elfter Heldentat gestohlen und - in Pontanos Version - nach Kampanien gebracht worden (I, Vv. 102-124). Die Verbindung von Herkules zu Neapel wird in mehreren Quellen heraufbeschworen und durch Pontanos Mythos zusätzlich bestärkt. ${ }^{156}$

Die aussergewöhnliche Beschaffenheit des Zitrusbaums wird am Schluss des ersten Buches erneut hervorgehoben, wenn davon erzählt wird, wie die Parzen den Bäumen Unsterblichkeit verliehen haben. Nach dem Tod des Adonis und auf Geheiss von Venus haben die Parzen die Fäden noch einmal zurückgesponnen. Damit konnten sie Adonis nicht wieder zum Leben erwecken, aber sie konnten den Baum, in den er sich verwandelte, unsterblich machen. So wurde er zu einem monumentum mirabile der Liebe und der Trauer und zu einem Motiv der Dichtung (I, Vv. 526-6o7).

Zu Beginn des zweiten Buches ruft der Erzähler die Plejaden und Personifikationen Neapels - wie wir sie bereits in Lepidina angetroffen haben - an:

153 Siehe die Verse 189-193 sowie 201-202 der Ekloge Meliseus in der Edition von CaSAnovaRoвin. Siehe ebenfalls IAcono, Il De hortis Hesperidum, S. 5 .

$154[\ldots]$ und erstaunt füllt sie sich die Brust mit schweren Früchten. // Die Früchte werden an dieser und an weiteren Stellen als staunenswerte beschrieben. Wie in den Aufzügen vier und fünf von Lepidina wird damit eine Ästhetik des Üppigen, Grossen, Massigen zelebriert, die auch erotisch unterlegt ist. Vgl. dazu II, Vv. 83-84.

155 Viele Texte Pontanos sind als Elegien verfasst, nicht nur auf seine verstorbene Frau, auch auf einzelne seiner Kinder, die verstorben sind, zum Beispiel die Jambici, die den Tod des Sohnes Lucius besingen.

${ }_{15}$ Insbesondere wird berichtet, Herkules sei von Spanien nach Neapel gekommen - was eine Identifikation des Helden mit Alfonso il Magnanimo ermöglichte. Siehe IAcono, Il De hortis Hesperidum, S. 10. Pontano erzählt weiter, die Zitrusbäume seien von den Wäldern Formias und den Stränden Gaetas, insbesondere aber von den Gärten der «Virginis Hormialae » empfangen und aufgenommen worden. Die Jungfrau habe Herkules gar ins Brautgemach eingeladen und von ihm den Baum mit den goldenen Früchten erhalten. Von da an habe der Zitrusbaum die Küste und die angrenzenden Hügel Kampaniens geschmückt. 
Sie sollen ihm dabei helfen, eine Dichtung zu schaffen, die Staunen und Bewunderung auslöst.

[...] Nunc o mihi, natae

Pleiones, astate atque aspirate canenti;

Vester honos agitur, vestro sub numine crescit

Hoc opus et vestris mea tempora cingite sertis;

Vos quoque adeste simul facilesque estote, puellæ

Hortorum memores; tuque, o mihi culta Patulci,

Prima adsis primosque mihi, dea, collige flores,

Impleat et socios tecum Antiniana quasillos:

Sic tibi perpetuum spiret rosa, floreat urna,

Scilicet urna, tui qua conditur umbra Maronis,

Ambrosiæ fundat rivos, det nectaris amnes

Mincius et niveos semper tibi pascat olores

Et lætata suos iteret tibi Mantua cantus,

Mantua dives avis, dives gonsagide prole,

Ac nova lucrinæ stupeant ad carmina cautes,

Sistat et ipsa suos mirata Neapolis amnes. ${ }^{157}$ (II, Vv. 7-22)

Eine neue Dichtung soll entstehen, die die lukrinischen Felsen in Staunen versetzt und die Flüsse Neapels zum Stillstand bringt. Die Dichtung ist eine Erneuerung des orphischen und des vergilschen Gesangs, aber sie ist auf Kampanien ausgerichtet, besingt die Eigenheiten der Gegend und setzt diese als (erstaunte) Zuhörerin ein.

Das zweite Buch setzt sich mehrheitlich aus botanischen Anleitungen zusammen. Diese lassen sich als Parallelen der poetologischen Kriterien, wie Pontano sie im Actius definiert, lesen. ${ }^{158} \mathrm{Zu}$ diesen Kriterien zählen

157 Jetzt, oh plejadische / Nymphen, steht mir bei und inspiriert meinen Gesang; / denn ich singe zu eurer Ehre, mein Werk entsteht unter / eurem göttlichen Willen und ihr schmückt meine Schläfen mit euren Blumengewinden; / und auch ihr Mädchen, Erinnerung der hesperischen Gärten, steht mir bei und / seid mir wohlgesinnt; und auch du, meine gebildete Patulcis, / komm als Erste zu mir und pflücke mir, du Göttliche, die ersten Blumen, / mit dir füllt Antiniana die gemeinschaftlichen Körbchen; / So duften die Rosen immerwährend für dich, es blüht die Urne, / wohlgemerkt jene Urne, in der die Überreste deines Vergil bestattet sind, / Ambrosia entspringt den Bächen, und Nektar gibt der Mincio seinen / Flüssen, und für dich weiden die weissen Schwäne, / und das erfreute Mantua erneuert für dich seine Gesänge, / Mantua, reich an Vorfahren, reich an Nachkommen der Gonzaga, / und es staunen die lukrinischen Felsen über die neuen Gesänge, / und bewundernd hält selbst Neapel seine Flüsse an.

${ }_{15} 8$ Es ist aber unbedingt zu beachten, dass die Texte über den Anbau der Zitrusbäume effektiv auch dem Leser-Gärtner als Hilfestellung dienen sollen. Eine rein allegorische Leseweise würde den Text verfremden und in eine Interpretationsstruktur zwängen, die so nicht gegeben ist. 
folgende: Freiheit und Vielfalt - inhaltlich, metrisch, kompositorisch, stilistisch -; Ausserordentlichkeit, Exzellenz, Erhabenheit und Würde; das Ineinanderfliessen von Realität und Fiktion; wundersame fiktive Inhalte; eine synästhetische und rhythmisch geformte Sprache; die rhetorischen Mittel des Vergleichs, der Metonymie und der Metapher, der Bildlichkeit, der Hyperbel und des Oxymorons.

Die Vielfalt der Gärten, die durch Kunstfertigkeit, Geduld, Energie sowie ständige Sorgfalt des Gärtners entsteht, wird gelobt. Über die neuen Formen zeigt sich sogar die Natur erstaunt. ${ }^{159}$

Ars igitur tempusque et vis innata perenni

Cura hominum nemora in lanas vertere, ut in hortis

E follis ramisque et diversis contextis

Iam videas fulgere novis aulaea figuris. ${ }^{160}$ (I, Vv. ${ }^{22-525)}$

[...] Paulatim artus formabit et inde

Ducet inumbratos signato in cortice vultus,

Occultas natura hominum miretur ut artes,

$[\ldots]^{161}\left(\mathrm{II}, \mathrm{Vv} .135^{-137}\right)$

Sed nec defuerint scisso qui codice adacto

Dilatent vulnus cuneo, mox vulnere crudo

Includant gemmas alilnæ stirpis alunnas;

Mox tenui obstringant vitta: non fit mora, longos

Emittunt ramos et silva litus obumbrant,

Exciso et veteri cono sua brachia fundunt,

Ac dorso alterius (mirum) nova pullulat arbos. ${ }^{162}$ (II, Vv. 384-39o)

159 Insbesondere im 16. und 17. Jahrhundert wurden die unzähligen, teilweise bizarren Formen der Zitrusfrüchte bestaunt - seien diese natürlich oder durch Züchtung entstanden. Die bizarrsten Früchte wurden mit Wachsformen nachgebildet und als Elemente der damaligen Wunderkammern geführt. Die Zitrusbäume verfügen über eine sehr komplizierte Botanik, die sich - zumindest damals - dem menschlichen Wissen noch nicht vollständig erschloss und deshalb als Wunder galt. Siehe AtTLEe, The Land Where Lemons Grow, S. 9.

16o Die Kunst, demnach, und die Zeit und die angeborene Kraft und die beständige / Fürsorge der Menschen kann die Hölzer in Wolle verwandeln, wie in den Gärten / Blätter und Äste sich unterschiedlich ineinaner schlingen / siehst du Teppiche in neuen Erscheinungsformen erstrahlen. // Vgl. auch II, Vv. 2-3, 373-375.

$161[\ldots]$ Nach und nach wird er seine Glieder formen / und in seiner Rinde werden die gezeichneten Formen eingekerbt sein, / sodass die Natur selbst über die geheimen Künste der Menschen staunt.

162 Es werden auch jene nicht fehlen, die, nachdem sie einen Schnitt in den Baustamm geritzt haben, / die Wunde mit einem Keil erweitern und bald in die frische Wunde / junge Knospen eines anderen Stammes einschliessen; / bald schnüren sie eine dünne Binde darum: Sogleich / bilden sich lange Äste aus und ein Wald wird die Küste beschatten, / 
Pontano legt den Fokus auf die «Industria umana», die Vielfalt entwirft, schafft und pflegt. ${ }^{163}$ Durch sie hat sich der menschliche Geist bis zu den Sternen erhoben, das Meer und die Erde unterworfen und sogar die Musen des Olymps zum Staunen gebracht:

Non igitur tantum pratis armenta, nec hærbæ Himbribus, aut apium debent examina rori, Quantum de rebus merita est Industria nostris; Cuius ope ingenium sese extulit et caput astris Admovit, maria ac terras sibi subdidit, ut nil Liquerit intentatum, ut summo e vertice Olympi Traxerit attonitas citrii ad spectacula Musas. ${ }^{164}$ (II, Vv. 425-431)

Non derit tanto felix fortuna labori, Crescet et immensum sata melle cleartias arbor, Ornabitque hortos, ac tanto munere læta Divinas natura hominum mirabitur artes, Quamquam adversa viris et fortibus invida cœptis. ${ }^{165}$ (II, Vv. 464-468)

Das menschliche Ingenium ist ausserordentlich und göttlich - die Natur staunt über die Gärten, die der Mensch schafft. Analog zu den Naturwelten schafft der Mensch in der Dichtung neue Imaginationswelten und macht diese den Lesern über die Sprache sinnlich zugänglich. Zentral für die Kreation neuer literarischer Welten ist das Mittel der Fiktion. Als Pendant neuer Kreuzungen und Züchtungen dient sie der mythologischen Einbettung auf der einen, der

an der Schnittstelle des alten Stammes spriessen seine Äste, / und auf dem Rücken des anderen Baumes - oh Wunder! - entsteht ein neuer.

163 Dass Pontano die Kreativität und Kunstfertigkeit des Menschen über die Natur setzt, sieht Tateo als Abwendung Pontanos von der platonischen Konzeption der Dichtung. Die Natur bzw. die Ideen haben in Letzterer einen höheren Stellenwert als die Kunst, die schlussendlich immer nur Abbild der Ideen und der Natur ist und sein kann. Siehe TATEO, La poetica, S. 347 .

164 So sind die Herden nicht so sehr den Weiden und die Gräser nicht / dem Regen, die Bienenschwärme nicht dem Tau verpflichtet, / sondern verdanken alles unserem Fleiss; / aus dessen Werken ist der Geist hervorgegangen und an die Sterne / herangerückt, er hat die Meere und die Landschaften unterworfen, sodass / er nichts unversucht liess, und vom höchsten Gipfel des Olymps / holte er die erstaunten Musen zur Schau der Zitrusbäume herbei.

165 Das Glück wird bei dieser grossen Arbeit nicht fehlen, / sodass der Zitrusbaum, satt vom Honig, gewaltig wachsen wird, / er wird die Gärten zieren und die Natur, dankbar für dieses / grosse Geschenk, wird die göttliche Fertigkeit der Menschen bestaunen, / auch wenn sie den kräftigen Menschen und ihren Unterfangen feindlich und neidisch gegenübersteht. 
Veranschaulichung der ausserordentlichen Wirkkraft des Zitrusbaums auf der anderen Seite. ${ }^{166}$

Eine weitere Analogie zwischen Baum und Dichtung lässt sich in der Klassifikation der Früchte und Stoffe erkennen. Von den Zitrusfrüchtem gibt es süsse und bittere Sorten. Klassischerweise sind das Bittere und das Süsse die zwei Seiten der Liebe, so auch bei Pontano (I, Vv. 336-340): Szenen der entzückten Liebe auf der einen, Trauer um den Verlust der Liebe auf der anderen Seite. Die beiden Leitthemen haben wir bereits an verschiedenen Stellen herausgearbeitet - die Beschreibung der Zitrusbäume bekräftigt sie erneut. Das Bittere und das Süsse werden hier zwar nicht explizit als erstaunliche Eigenschaften dargestellt, aber sie sind Teil der vielfältigen Ausprägung der Zitrusfrucht, die - wie wir gesehen haben (I, V. 317) - als Ganzes bewundert wird.

Die Tugendhaftigkeit des Actius, die sich in der harmonischen Mitte situiert, findet im Lehrgedicht ein Pendant in der Auswahl des passenden Ortes: Dieser soll weder zu sehr der Sonne ausgesetzt noch ihr entzogen, weder zu feucht noch zu trocken, weder zu viel noch zu wenig Wind ausgesetzt sein. Natürlich sieht Pontano für die Zitrusbäume eine südlich gelegene, küstennahe Gegend als optimalen Pflanzungsort vor - damit hebt er sich von den nördlichen Gegenden ab, die zwar reich an Kriegen, Heroen und Dichtern seien (I, V. 203), aber eben grösstenteils unpassend für die Pflanzung des Zitrusbaums. Er konstituiert seine Dichtung als Dichtung des Südens, gebunden an die landschaftlichen und meteorologischen Gegebenheiten Kampaniens.

Die Form der Bäume soll nicht dem Zufall überlassen bleiben, sondern wird vom Gärtner mit Hilfsmitteln (Pfählen oder Eisenstäben) so gestaltet, wie er sie sich wünscht:

[...] iniice ferrum,

Caede manu, ne in luxuriem fundatur inanem;

Nam veniet quocumque voces. ${ }^{167}$ (I, Vv. 255-257)

Nicht ohne Grund wird hier mit «quocumque voces» («wohin du sie rufen wirst») die Stimme eingefügt und damit die Brücke von der Garten- zur Spracharbeit geschlagen: Baum und Gedicht fügen sich in die Form, die ihnen

166 So war beispielsweise Neptun von dem Duft der Zitronen derart betört, dass er der verzweifelten Alkyone zu Hilfe eilte, sie vor dem Tod rettete und ihr die zuvor verweigerte Liebe zukommen liess (II, Vv. 196-217). Der Duft löst eine Veränderung aus und lässt Liebe entstehen.

$167[\ldots]$ setze das Eisen an / und schneide die Äste, sodass sie nicht vergeblich üppig hervorspriessen; / und sie werden dir folgen, wohin du sie rufst. 
vom Gärtner oder Dichter gegeben wird. Diese Form wird an späterer Stelle als harmonisch dahinfliessend und einer Regel gehorchend beschrieben (I, Vv. 416-417). Das Richten der Aufmerksamkeit auf die kleinsten Teile - beim Baum Äste und Blätter, beim Gedicht Silben und Verse - ist eine Voraussetzung für die Entstehung der admiratio, denn diese überträgt sich von den kleinsten Elementen Ebene um Ebene auf das gesamte Werk. An der Form lässt sich auch die Erhabenheit der Bäume erkennen: Der Baum wurde gekrümmt aus den hesperischen Garten nach Kampanien gebracht, erst durch die Kultivierung und Anpassung hat er seine aufrechte, elegante Form erhalten.

Der Mensch - ob Gärtner oder Poet - steuert seine Schöpfungen. Gegen Ende des zweiten Buches wird dies durch ein Beispiel bekräftigt, das auf der einen Seite die Arbeit des (Garten-)Künstlers hervorhebt, auf der anderen Seite das Verhältnis von Tradition und Innovation darlegt. Werden zwei Äste von verschiedenen Bäumen zusammengebunden, wachsen sie ineinander. Sie ernähren sich voneinander, um sich nach und nach ganz zu vermischen: ein Sinnbild für den Einbezug fremder Quellen in die eigene Dichtung. Die Quellen werden adaptiert und fügen sich ganz in die neue Umgebung ein.

Iam videas docili e planta pubescere prolem Frugiferam; tunc carpe manu, tunc erue ferro Quod superat matre e sterili et blandire novellis: Mira fides, nitidis palmes se tollet alunnis. ${ }^{168}$ (II, Vv. 403-406)

Quando et inexpertum nihil ars sinit, hoc quoque et hortis

Accedat, vel dictu etiam mirabile, de quo Quamvis longe audax, quanquam sibi conscius usus

Addubitet: ramum focunda e matre revulsum Decutiens capito; cæsum mox undique librum Æquatis ferro spatiis dextraque volentem Exuito; inde pari confossum vulnere dorsum Stipitis alterius nudato, et veste recenti Induito, ut coeant extremis partibus oræ, Vestis et e lento mollescant vulnera limbo; Ulmea dehinc teneres indatur cingula plagis, Vinculaque ingentis committant vulneris ora, Vestiat et frondes truncum toga, pellat ut himbres, Arceat ut soles et sævæ uredinis iram.

Dii, facinus mirandum: hærenti e cortice cortex Ipse novus victum medium rapit, atque supernis

168 Bald wirst du aus der gelehrigen Pflanze einen fruchtbaren Sprössling / heranwachsen sehen; dann pflücke mit der Hand und grabe mit dem Eisen aus, / was die ertraglose Mutter überragt und pflege die jungen Pflanzen: / Ein Rebstock erhebt sich, wunderbares Ehrenwort, aus den stattlichen Jünglingen. 
Instillant ramis, quæque in sua pabula traxit

Exuriens alimento suo ut de fonte refusa

Ipse suis infundat alunnis, ipse et amicum

Irroret lac, ut sensim in sua nomina vertat

Ramosque frondesque et eodem semina fœetu,

$[\ldots]^{169}(\mathrm{II}, \mathrm{Vv} .476-496)$

Wie Lepidina erweist sich De hortis Hesperidum als überaus reichhaltige Quelle, um Pontanos Poetik der admiratio entweder in actu oder in der Form botanischer Metaphern und Allegorien anzutreffen. Analog zu Lepidina zeigt sich die kreative Mythologisierung als zentrales Verfahren des Textes - das Hinzufügen eines mythischen und metamorphotischen Ursprungs des Zitrusbaums, der zudem in den tragischen Liebesmythen des Orpheus und der Venus gründet, bildet die entscheidende Prägung des Textes. Der Zitrusbaum wird zum Symbol der Dichtung, seine Eigenschaften werden auf die Dichtung übertragen: Er wird bewundert, weil er immergrün ist - genauso «blüht» die Dichtung ewiglich und vergeht nicht. Der Zitrusbaum wird von der Ehefrau bestaunt und verführt das Paar zu Liebesstunden, zugleich steht er für die Erinnerung an die verlorene Liebe. Genauso wie der Zitrusbaum ist die Dichtung in die Region Kampaniens eingebettet; so stellt diese nicht nur das topographische und mythologische Material dar, sondern ist ebenso erstaunte Zuhörerin desselben. Vervollständigt wird das Bild durch den Dichter in der Rolle des Gärtners, dessen Ingenium von der Natur und den Göttern gleichermassen inspiriert und gepriesen wird.

169 Weil die Kunst nichts unversucht lässt, widmet sie sich auch den / Gärten, nur schon es auszusprechen ist wunderbar, / und wenn auch noch so stolz darauf, zweifelt sie / am effektiven Nutzen: brich aus einer gesunden Mutterpflanze / einen Ast ab; sobald er abgeschlagen ist und du mit dem Messer die Rinde überall / und in gleichen Abständen entfernt hast, kannst du ihn mit den Händen / befreien, auf gleiche Weise befreist du den durchbohrten Rücken / eines anderen Zweiges, und bekleide ihn mit dem neuen / Gewand, sodass die äussersten Teile zusammenkommen / und die Wunden weich werden am klebrigen Saum des Kleides; / danach bindest du einen Gürtel aus Ulmen um die Wunden, / binde die offenen Stellen zusammen, sodass die grossen Schnitte zusammenkommen, / kleide den Stamm mit Blättern ein, um den Regen abzuhalten / und die Sonne fern und den Zorn des wütenden Getreidebrands. / Oh ihr Götter, welch erstaunliche Handlung: Die neue Rinde ernährt sich / von der Nahrung der anderen Rinde, an dieser haftend, und führt diese bis in die / äussersten Äste, was sie als Nahrung bezieht, / kehrt sie um und giesst sie in ihre Triebe, sie führt die günstige / Milch ein, sodass sie allmählich die Äste, / die Blätter sowie die Samen und die Früchte in ihre Gattung wendet, [...] 


\subsection{Konklusion}

Die drei in diesem Kapitel untersuchen Werke - Actius, Lepidina und De hortis Hesperidum - weisen auf sprachlicher und auf inhaltlicher Ebene eine unverwechselbare Eigenständigkeit auf. Der Raum für diese Vielfalt wird durch den poetologischen Dialog und dessen Ausrichtung auf die admiratio konstituiert. Insbesondere die literarischen Werke zeugen von einer grossen Fantasie und betonen damit das Mittel der Fiktion, das im Actius als eines der tragendsten Bestandteile einer Poetik der admiratio ausgewiesen wurde.

Trotz aller Vielfalt bewegen sich die Texte in einer gemeinsamen Sphäre, deren Teile einen spezifischen Beitrag zur admiratio leisten. Als Eckpunkte dieser Sphäre lassen sich folgende Eigenschaften nennen: Augenfällig ist die topographisch geprägte Mythologie, die sich aus Bruchstücken antiker Mythen, verwandelt und erweitert um neue Inhalte und Wendungen, zusammensetzt. Der verwendete Mythenschatz basiert grösstenteils auf Geschichten von Helden und Göttern, die sehnsüchtig ihrer Geliebten gedenken oder um deren Verlust trauern (Venus und Adonis, Orpheus und Eurydike, in loser Andeutung Dido und Aeneas). Pontano selbst fügt sich in diese Gruppe von trauernden Liebenden ein und macht sich, seine Leidenschaft und seine Liebe - als reale Persönlichkeit und als literarische Figur - zum Thema. Die Mythopoetik, die Liebe bzw. deren Verlust sowie das geschickte Changieren zwischen mythischer und realer Lebenswelt stehen, wie wir in allen Texten nachvollziehen konnten, im Dienst der admiratio. Eine weitere zentrale Eigenschaft ist der wirkungsästhetische Fokus der Texte, der sich auf unterschiedlichen Ebenen niederschlägt: Die Texte präsentieren kreative, neu geformte und verwunderliche Welten und Figuren - sie regen den Leser in seiner Imaginationskraft beständig an. Die Texte sind überaus bildlich und sinnlich, sie zielen darauf, einen körperlichen Eindruck - sei dieser visuell, olfaktorisch oder auditiv - zu hinterlassen. Besonders ausgeprägt ist die auf das Staunen ausgerichtete Leserführung. Der Blick des Lesers wird auf die aussergewöhnliche Gestalt der Figuren in vielen Fällen ist es die Schönheit der (weiblichen) Körper, es kann aber auch deren Monstrosität sein - oder aber auf die Dichtung oder den Dichter gerichtet.

Zusätzlich zu den theoretischen Kriterien und Analysen kann ich als Leserin anführen, dass die Erfahrung der Texte quasi permanent von Staunen geprägt ist, und es ist - wie es in De hortis Hesperidum beschrieben wird - insbesondere der Dichter, dessen Schaffenskraft man bestaunt, während die vielen aussergewöhnlichen, neuen, prallen Bilder vor dem inneren Auge vorüberziehen. Pontano ahmt nicht nach, sondern schafft Neues, transformiert seine 
literarischen Quellen genauso wie seine reale Lebenswelt in unverwechselbare poetische Gebilde. ${ }^{170}$

Im Gegensatz zu Poliziano, für dessen Texte die admiratio zwar als strukturbildendes Prinzip herausgearbeitet werden konnte, der aber keine explizite Poetik der admiratio vorlegte, hat Pontano im Dialog Actius die admiratio als höchstes Ziel der Dichtung definiert. Poliziano stellt der admiratio die Prinzipien der variatio und eine kreative Form der imitatio zur Seite, Pontano leitet die admiratio zudem aus der metrischen und syntaktischen Komposition sowie der bewusst eingesetzten Fiktionalisierung her. Beide Autoren binden historische Gegebenheiten in mythologisierter Form in ihre Texte ein, wobei Pontano zudem verstärkt seine eigene Lebenswelt - insbesondere die Liebe zu seiner Frau, deren Tod sowie seine neapolitanische Umwelt - in die Dichtung einbringt.

Die Dichtung beider Autoren situiert sich vor einem enkomiastischen Hintergrund: Polizianos Dichtung entsteht als Lob der Medici, diejenige Pontanos zugunsten des aragonischen Königreiches. Ist es bei Poliziano vornehmlich die Bewunderung der mediceischen Persönlichkeiten, die als Inspiration seiner Texte dienen, überlagert Pontano den enkomiastischen mit dem topographischen Diskurs, insofern als er Kampanien als Inspirationsquelle und zentrales Motiv in seine Werke aufnimmt. Sowohl die Medici insbesondere Giuliano de' Medici - als auch Kampanien werden zu Mythen transformiert, wodurch das Erstaunliche ihrer Charaktere betont wird. Die mythische Fiktionalisierung transportiert die admiratio von der realen in die literarische Welt.

Der Ursprung der Dichtung wird von beiden Autoren in der griechischen Mythologie und Dichtung verortet, allen voran bei Orpheus und Homer. Diese beiden Urdichter berichten Erstaunliches und vermögen damit ihre Zuhörer zu erstaunen. Sowohl für Poliziano wie auch für Pontano bildet die erstaunliche, magisch-prophetische Sprache der Ursprungsdichtung den Anfang der Zivilisation; erst nach und aus ihr sind die Regeln für das Zusammenleben, die einzelnen Wissenschaften, das Bewusstsein für das Göttliche sowie weitere Redeformen entstanden. Innerhalb zeitgenössischer philosophischer Texte markieren diese Darstellungen insofern eine Wende, als die Dichtung nicht aus dem Staunen über das Göttliche entsteht und dieses zu vermitteln sucht, sondern über das Erstaunliche der poetischen Schöpfung das Göttliche überhaupt erst erfahrbar wird.

170 Zum Dichter als Schöpfer neuer, eigener Realitäten siehe FERRAÙ, Pontano critico, S. 43. 
Charakteristisch für beide Autoren ist die Zusammenführung der griechischen mit der lateinischen Tradition, wobei Poliziano diese in Vergil kulminieren lässt und sich als dessen Nachfolger darstellt. Pontano hingegen begründet durch die griechisch-lateinische Tradition eine neue, neapolitanische Dichtung, als deren Vertreter er sich selbst nennt. Damit begründen beide Autoren ihre „eigene“ Dichtung, die zwar auf literarischen Vorbildern aufbaut, aber neue, eigenständige Formen aufweist.

In den Stanze genauso wie in Lepidina stellt das Staunen ein handlungstreibendes Moment dar, insofern als das innamoramento zwischen Iulio und Simonetta sowie die Aufforderung zum Turnier - in Lepidina die Betrachtung der (ausserordentlichen) Hochzeitsgäste - vom Staunen angeleitet werden. Der Blick der Figuren ist auf das Erstaunliche gerichtet, wobei das Erstauntsein durch einen dem Text inhärenten Gestus des Staunens auf die Leser übertragen wird. Mündet Polizianos Staunen im ersten Buch der Stanze in der Betrachtung der Kunst - wodurch insbesondere die bildliche Kraft der Sprache hervorgehoben wird -, betont Pontano in Lepidina wiederholt das erstaunliche Ausdrucksvermögen dichterischen Gesangs - so von Parthenope, Meliseus und Antiniana. Trotzdem gilt auch sein Fokus dem bildgebenden Charakter der Sprache, indem er zum einen selbst eine überbordend bildliche Sprache schafft, zum anderen bevorzugt die bildlichen Stilmittel der Metapher und der Allegorie verwendet.

Das Verhältnis von Kunst und Natur wird bei beiden Autoren, wenn auch auf unterschiedliche Art und Weise, thematisiert. Poliziano stellt überdie Ekphrasis der Kunst die kreative und imaginative Kraft der Dichtung aus. Pontano setzt die Natur als vielfältiges Vor- und Sinnbild der Dichtung ein und zeigt über fantasievolle Nachbildungen - insbesondere durch Personifizierungen die Freiheit und die Kraft der dichterischen Gestaltung auf. Die Natur wird sowohl bei Poliziano als auch bei Pontano von den kunstvollen Schöpfungen der Dichtung übertroffen. Sie ist dabei nicht nur Vorbild von diesen, sondern zugleich erstaunte Zuhörerin und Betrachterin.

Die Silvae genauso wie De hortis Hesperidum stellen poetologische Lehrgedichte in der Nachfolge antiker Autoren dar. Der "trockene" Lehrstoff wird durch Mythologisierung und Fiktionalisierung sowie durch die bewundernde Haltung des Erzählers von Beginn an als erstaunlicher präsentiert - ganz im Sinne von Aristoteles, der in seiner Rhetorik Lernen und Staunen aneinanderkoppelt, insofern als das Staunen die Begierde zu lernen weckt und beides zusammen Freude bereitet. ${ }^{171}$ Dank ihrer kreativen poetischen Gestaltung

171 Rhet., 1371a-b. 
sind die Lehrgedichte keine Regelwerke, sondern Vermittler der poetischen Begeisterung. Auch der Dialog Actius wurzelt in erster Linie in der Bewunderung von Vergils Texten, woraus zwar einige poetologische Vorgaben abgeleitet werden, diese aber immer noch in einem solchen Masse offenbleiben, dass sich sie fern einer Regelpoetik situieren und der dichterischen Gestaltung viel Raum lassen. 